\title{
RalGPS2 Interacts with Akt and PDK1 Promoting Tunneling Nanotubes Formation in Bladder Cancer and Kidney Cells Microenvironment
}

\author{
Alessia D'Aloia ${ }^{1}$ D, Edoardo Arrigoni ${ }^{1}{ }^{(D}$, Barbara Costa $^{1}\left(\mathbb{D}\right.$, Giovanna Berruti $^{2}$, Enzo Martegani ${ }^{1,3}$, \\ Elena Sacco ${ }^{1,3}$ (D) and Michela Ceriani ${ }^{1,4, *(D)}$ \\ 1 Department of Biotechnology and Biosciences, University of Milano-Bicocca, Piazza della Scienza 2, \\ 20126 Milan, Italy; alessia.daloia@unimib.it (A.D.); edoardo.arrigoni@unimib.it (E.A.); \\ barbara.costa@unimib.it (B.C.); enzo.martegani@unimib.it (E.M.); elena.sacco@unimib.it (E.S.) \\ 2 Department of Biosciences, University of Milan, Via Celoria 26, 20133 Milan, Italy; giovanna.berruti@unimi.it \\ 3 SYSBIO-ISBE-IT-Candidate National Node of Italy for ISBE, Research Infrastructure for Systems Biology \\ Europe, 20126 Milan, Italy \\ 4 Milan Center for Neuroscience (NeuroMI), University of Milano-Bicocca, Piazza dell'Ateneo Nuovo 1, \\ 20126 Milano, Italy \\ * Correspondence: michela.ceriani@unimib.it; Tel.: +39-0264483544
}

Citation: D'Aloia, A.; Arrigoni, E.; Costa, B.; Berruti, G.; Martegani, E.; Sacco, E.; Ceriani, M. RalGPS2 Interacts with Akt and PDK1 Promoting Tunneling Nanotubes Formation in Bladder Cancer and Kidney Cells Microenvironment. Cancers 2021, 13, 6330. https://doi.org/10.3390/ cancers 13246330

Academic Editors: David Wong and Donna Hansel

Received: 27 October 2021

Accepted: 14 December 2021

Published: 16 December 2021

Publisher's Note: MDPI stays neutral with regard to jurisdictional claims in published maps and institutional affiliations.

Copyright: (c) 2021 by the authors. Licensee MDPI, Basel, Switzerland. This article is an open access article distributed under the terms and conditions of the Creative Commons Attribution (CC BY) license (https:/ / creativecommons.org/licenses/by/ $4.0 /)$.
Simple Summary: Cell-to-cell communication in the tumor microenvironment is a crucial process to orchestrate the different components of the tumoral infrastructure. Among the mechanisms of cellular interplay in cancer cells, tunneling nanotubes (TNTs) are dynamic connections that play an important role. The mechanism of the formation of TNTs among cells and the molecules involved in the process remain to be elucidated. In this study, we analyze several bladder cancer cell lines, representative of tumors at different stages and grades. We demonstrate that TNTs are formed only by mid or high-stage cell lines that show muscle-invasive properties and that they actively transport mitochondria and proteins. The formation of TNTs is triggered by stressful conditions and starts with the assembly of a specific multimolecular complex. In this study, we characterize some of the protein components of the TNTs complex, as they are potential novel molecular targets for future therapies aimed at counteracting tumor progression.

Abstract: RalGPS2 is a Ras-independent Guanine Nucleotide Exchange Factor for RalA GTPase that is involved in several cellular processes, including cytoskeletal organization. Previously, we demonstrated that RalGPS2 also plays a role in the formation of tunneling nanotubes (TNTs) in bladder cancer 5637 cells. In particular, TNTs are a novel mechanism of cell-cell communication in the tumor microenvironment, playing a central role in cancer progression and metastasis formation. However, the molecular mechanisms involved in TNTs formation still need to be fully elucidated. Here we demonstrate that mid and high-stage bladder cancer cell lines have functional TNTs, which can transfer mitochondria. Moreover, using confocal fluorescence time-lapse microscopy, we show in 5637 cells that TNTs mediate the trafficking of RalA protein and transmembrane MHC class III protein leukocyte-specific transcript 1 (LST1). Furthermore, we show that RalGPS2 is essential for nanotubes generation, and stress conditions boost its expression both in 5637 and HEK293 cell lines. Finally, we prove that RalGPS2 interacts with Akt and PDK1, in addition to LST1 and RalA, leading to the formation of a complex that promotes nanotubes formation. In conclusion, our findings suggest that in the tumor microenvironment, RalGPS2 orchestrates the assembly of multimolecular complexes that drive the formation of TNTs.

Keywords: tunneling nanotubes; bladder cancer; kidney; microenvironment; stress condition; RalGPS2; Akt; PDK1 


\section{Introduction}

According to Global Cancer Statistics 2020 [1], bladder and kidney cancers together accounted for over 1 million new cases and about 400.000 new deaths worldwide in 2020.

Most new cases of cancer are diagnosed when tumors are localized and confined within the organ affected, with a relatively high 5-year survival rate ( $95 \%)$. However, many patients experience relapse within 5 years, some of them progressing to invasive disease with a significant drop in life expectancy (5-year relative survival rate of $13 \%$ and $6 \%$ for metastatic kidney and bladder cancer, respectively) [2-4].

In particular, the cost of therapies for bladder cancer is the highest, compared to other cancers in the United States [5,6] and Europe, and has a huge impact on public health costs [7].

Novel safe and effective therapeutic approaches for the treatment of bladder cancer are urgently needed. To this end, it is necessary to further investigate the molecular mechanisms underlying tumor progression, invasion and metastasis formation and identify new pharmacological targets.

In the tumor microenvironment, cell-to-cell communication and signaling mechanisms play a pivotal role, enabling the exchange between healthy and cancer cells of signaling molecules, metabolites and organelles, such as mitochondria. Such exchange mechanisms enable cancer cells to affect the healthy ones, causing the latter to develop tumor-supportive traits [8].

Tunneling nanotubes (TNTs) are highly-dynamic membrane protrusions that enable cells to directly communicate with each other over long distances $(>120 \mu \mathrm{m})[9,10]$. Indeed, TNTs are long-range cytoplasmic channels that enable the exchange between cells of cargoes containing organelles, molecules, proteins, pathogens, miRNAs and ions [11-18]. Lou et al. [19] first demonstrated the presence of TNTs in tumors in human malignant pleural mesothelioma. Over the years, it has become clear that these TNTs are involved in intercellular communication processes during early development, cell migration, stem cell-mediated homeostasis and regeneration, as well as advanced neurodegeneration, cancer progression and metastasis development [16]. The formation of TNTs occurs in several cell types, including neuronal cells, epithelial cells and most cells of the immune system [20-26]. TNTs are also present in tumors, such as urothelial carcinoma, cervix carcinoma, breast and colon cancer, glioblastoma, leukemia, mesothelioma [10,19], ovarian cancer [27], osteosarcoma [28] and pancreatic cancer [29]. TNTs are not branched and are suspended above the matrix [26], they can fall into two different types, each of which can be present simultaneously in the same cell type [30]: (i) type I, essentially made of actin, is formed by cells within their surroundings and ii) type II, made of tubulin and cytokeratin filaments, which is formed by the detachment of two cells that are already connected [31,32]. Type I are short $(100-200 \mathrm{~nm})$, thin $(\leq 0.7 \mu \mathrm{m})$ and mostly dynamic structures, while type II are long $(1 \mu \mathrm{m})$, thick $(\geq 0.7 \mu \mathrm{m})$ and stable [33]. TNTs can be closed or open-ended; the latter case allowing the cytoplasm of the two connected cells to mix $[9,34]$. However, the molecular mechanisms responsible for the formation of TNTs have not been fully elucidated yet. Gousset et al. have demonstrated that TNTs formation is dependent on the unconventional motor protein myosin $X$, which interacts with several transmembrane proteins [35]. Specifically, Gousset et al. showed that the transmembrane MHC class III protein leukocyte-specific transcript 1 (LST1) recruits to the plasma membrane the actin cross-linking protein filamin and interacts with myosin, myoferlin and M-Sec [36]. The latter, M-Sec, also known as TNF $\alpha$ IP2 (tumor necrosis factor $\alpha$-induced protein), together with the RalA small GTPase, promotes the assembly of a multi-protein complex (exocyst complex), which can induce the formation of functional TNTs [37]. TNTs formation in different cell types and models depends on different signaling mechanisms [38]. For instance, it has been shown that elevated levels of p53 in astrocytes are essential for TNTs formation, though this is not the case in other cell types, such as pheochromocytoma PC12 cells [33,39]. Furthermore, in 2018, our group demonstrated, in 5637 bladder cancer cell lines, the role of RalGPS2 (Ral GEF with PH domain and SH3-binding motif 2), a 
Ras-independent guanine exchange factor (GEF) for the GTPase RalA, in TNTs formation under low serum condition [40]. Although in normal serum conditions, RalA GTPase is predominantly activated by Ral guanine nucleotide dissociation stimulator (RalGDS), Ras-dependent GEFs activated by Ras GTPase [41-43], once activated, RalA interacts with Sec5, promoting the assembly of the exocyst complex and regulating exocytosis and cell proliferation. Aside from this role, RalGPS2 also affects protein kinase B (Akt) activation, leading to its phosphorylation. Phospho-Akt (Akt P) regulates, in turn, TNTs formation through the mechanistic target of rapamycin (mTOR) pathways, triggering F-actin polymerization and promoting TNTs development [44].

In this work, we investigated TNTs formation in bladder cancer cell lines at different stages and grades, and we could demonstrate that cancer cells at mid or high -stages generate functional TNTs, which are able to exchange mitochondria. Moreover, in 5637 cell lines, RalA GTPase and LST1 are transported through TNTs. Finally, our data demonstrate, both in 5637 and HEK293 cell lines, that RalGPS2 GEF is crucial for TNTs development through the assembly of molecular machinery formed by Akt and PDK1, in addition to LST1 and RalA.

\section{Materials and Methods}

\subsection{Plasmids and Constructs}

The plasmid expressing the fusion protein GFP-RalGPS2 was described previously [45]. The pEGFP-C1 vector was purchased from Clontech (Clontech Laboratories Inc., Mountain View, CA, USA). The mCherry-RalA expression construct [46] was kindly provided by J. Camonis (CNRS Inserm Institut Curie, INSERM U830, Paris, France). The mCherryLST1 expression construct [36] was kindly provided by C. Schiller (Department of Biology II, Ludwigs-Maximilians-Universität München, Großhadernerstr. 2, 82,152 PlaneggMartinsried, München, Germany).

\subsection{Antibodies}

Mouse anti-RalA antibodies (R23520) were from BD Transduction Laboratories (San Jose, CA, USA; dilution 1:1000). Anti-RalGPS2 rabbit antibodies have been described in a previous article (dilution 1:3000) [40,45]. Rabbit primary anti-GAPDH (\#2118; dilution 1:3000), rabbit monoclonal Phospho-Akt (Ser473) (D9E; dilution 1:1000) and polyclonal antiAkt (C67E7; dilution 1:1000) antibodies were purchased from Cell Signaling (Cell Signaling Technology, Danvers, MA, USA). The mouse monoclonal anti-Sec5 (F-7; dilution 1:200), anti-PDK1 (4A11F5; dilution 1:200), anti-Phospho-p53 (D-9; dilution 1:200) and TNF $\alpha$ IP2 (F6; dilution 1:1000) antibodies were obtained from Santa Cruz Biotechnology (Santa Cruz Biotechnology, Dallas, TX, USA). Anti-LST1 monoclonal antibodies (dilution 1:200) were previously described [36,47]. The secondary antibodies for western blot, peroxidaseconjugated sheep anti-mouse (515-035-003), donkey anti-rabbit (711-035-152) and antirat (712-036-150) polyclonal antibodies, were obtained from Jackson Ltd. (Jackson Ltd., Philadelphia, PA, USA; dilution 1:5000).

\subsection{Cell Cultures}

Grade 2 RT112 (stage pTa) and 5637 (stage not reported (nr)) bladder cancer cell lines were obtained from the American Type of Culture Collection (ATCC, Manassas, VA, USA). Grade 1-2 RT4 (stage pT1) and grade 3 HT1376 (stage $\geq$ pT2) bladder cancer cell lines were kindly provided by R. Vago (Urological Research Institute, division of experimental oncology, IRCCS, San Raffaele Hospital, Milan, Italy). Grade nr UMUC-3 (stage pT2-4) and grade 3 J82 (stage pT3) bladder cancer cell lines were purchased from Elabscience (Elabscience Biotechnology Inc., Houston, TX, USA). For bladder cancer cell lines classification, we referred to Zuiverloon et al. [48].

Cell lines were grown in RPMI-1640 medium (Merck Life Science, Darmstadt, Germany) supplemented with heat-inactivated 10\% fetal bovine serum (FBS, Gibco-ThermoFisher, Waltham, MA, USA), $2 \mathrm{mM}$ glutamine, $100 \mathrm{U} / \mathrm{mL}$ penicillin and $100 \mathrm{mg} / \mathrm{mL}$ streptomycin, 
at $37^{\circ} \mathrm{C}$ in a humidified atmosphere of $5 \% \mathrm{CO}_{2}$ (unless specified otherwise, cells were maintained under these conditions). Cells were passed using trypsin-ethylenediaminetetraacetic acid (EDTA). Live imaging was performed with the Operetta CLS ${ }^{\mathrm{TM}}$ High-Content Analysis System (PerkinElmer, Inc, Waltham, MA, USA). Unless otherwise indicated, cell assays were performed in experimental medium: Dulbecco's modified Eagle's medium (DMEM) $w / o$ phenol red (Gibco ${ }^{\mathrm{TM}}-$ Thermo Fisher Scientific), FBS 10\%, $10 \mathrm{mM}$ glucose, $2 \mathrm{mM}$ glutamine, $100 \mathrm{U} / \mathrm{mL}$ penicillin and $100 \mathrm{mg} / \mathrm{mL}$ streptomycin (unless specified, all reagents were from Merck Life Science). HEK293 Phoenix, human embryonic kidney cell line, kindly provided by prof. Renata Zippel (University of Milan, Italy), was grown at $37^{\circ} \mathrm{C}$ and $5 \%$ $\mathrm{CO}_{2}$ in DMEM (Euroclone, Pero, Italy) supplemented with 10\% FBS, 2 mM glutamine, $100 \mathrm{U} / \mathrm{mL}$ penicillin and $100 \mathrm{mg} / \mathrm{mL}$ streptomycin (all Euroclone, Pero, Italy).

\subsection{Tunneling Nanotubes Analysis in Bladder Cancer Cell Lines}

RT4, RT112, 5637, HT1376, UMUC-3 and J82 cells were plated at a density of $1 \times 10^{4}$ cells / well on CellCarrier Ultra 96-well Microplates (PerkinElmer, Inc, Waltham, MA, USA) in $100 \mu \mathrm{L}$ of the experimental medium at $37^{\circ} \mathrm{C}$ and $5 \% \mathrm{CO}_{2}$. After $24 \mathrm{~h}$, cell images were acquired using Operetta CLS ${ }^{\mathrm{TM}}$ (PerkinElmer, Inc, Waltham, MA, USA) equipped with $63 \times$ immersion objective in brightfield and Digital Phase Contrast (DPC) at $37{ }^{\circ} \mathrm{C}$ and $5 \% \mathrm{CO}_{2}$. Cells were carefully examined for the presence of tunneling nanotubes. We considered as positive any cell with at least one TNT. For quantitative determination, the percentage of cells forming nanotubes was calculated. About 200 cells, derived from different view fields of a plate, for each experiment were analyzed. The analysis was performed at the magnification described above. Experiments were performed in triplicate. Data were analyzed using GraphPadv6.0 software (San Diego, CA, USA) using ANOVA followed by Tukey's test for group comparison. $p<0.05$ was considered statistically significant.

\subsection{Mitochondrial Transfer via TNTs}

5637, HT1376, UMUC-3 and J82 cells were plated at a density of $1 \times 10^{4}$ cells/well on Cell Imaging 24-well Plates (Eppendorf, Hamburg, Germany) in $500 \mu \mathrm{L}$ of the experimental medium at $37^{\circ} \mathrm{C}$ and $5 \% \mathrm{CO}_{2}$. After $24 \mathrm{~h}$, cells were stained with $200 \mathrm{nM}$ MitoTracker ${ }^{\mathrm{TM}}$ Green FM (Invitrogen ${ }^{\mathrm{TM}}$ Thermo Fisher Scientific, Waltham, MA, USA) in an FBS-free medium for $20 \mathrm{~min}$ at $37^{\circ} \mathrm{C}$ and $5 \% \mathrm{CO}_{2}$. To assess active mitochondria, cells were plated as previously described and, after $24 \mathrm{~h}$, stained with 200 nM MitoTracker ${ }^{\mathrm{TM}}$ Green FM and 100nM Tetramethylrhodamine, Ethyl Ester, Perchlorate (TMRE, Invitrogen ${ }^{\mathrm{TM}}$ Thermo Fisher Scientific, Waltham, MA, USA), in FBS-free medium for $20 \mathrm{~min}$ at $37^{\circ} \mathrm{C}$ and $5 \%$ $\mathrm{CO}_{2}$. Before image acquisition, the staining medium was replaced with the experimental medium. Cell images were acquired using Operetta CLS ${ }^{\text {TM }}$ (PerkinElmer, Inc, Waltham, MA, USA) equipped with $63 \times$ immersion objective in brightfield, Digital Phase Contrast (DPC) and fluorescence to detect MitoTracker. The instrument was set at $37^{\circ} \mathrm{C}$ and $5 \%$ $\mathrm{CO}_{2}$. Cells were carefully scored for the presence of mitochondria within TNTs. To perform quantitative determination, the percentage of cells able to exchange mitochondria via TNTs was calculated. About 200 cells for each experiment were assessed and data analyzed using GraphPadv6.0 software (San Diego, CA, USA) employing ANOVA followed by Tukey's test for group comparison. $p<0.05$ was considered statistically significant.

\subsection{Transfection}

Transient transfection of 5637 cells was performed with mCherry-RalA or mCherryLST1 or GFP-RalGPS2 expression vectors, as previously described [40].

\subsection{Time-Lapse Imaging}

5637 cells were seeded at the concentration of $1 \times 10^{4}$ cells/well on Cell Imaging 24-well Plates (Eppendorf, Hamburg, Germany) in $500 \mu \mathrm{L}$ of the experimental medium at $37{ }^{\circ} \mathrm{C}$ and $5 \% \mathrm{CO}_{2}$. After $24 \mathrm{~h}$, cells were transfected as described above, and the day after time-lapse imaging was performed using Operetta CLS ${ }^{\mathrm{TM}}$ (PerkinElmer, Inc, Waltham, MA, 
USA) equipped with a $63 \times$ immersion objective. The instrument was set up to capture images of each chosen field every $2 \mathrm{~s}$, in brightfield and green, or red fluorescent channels, for $10 \mathrm{~min}$ at $37{ }^{\circ} \mathrm{C}$ and $5 \% \mathrm{CO}_{2}$.

\subsection{Western Blot Analysis}

Western blot analyses were performed as previously described [40]. Briefly, signals were detected using peroxidase-conjugated secondary antibodies; and immunoblots were developed using ECL Westar Nova 2.0 detection system (Cyanagen, Bologna, Italy). Original western blots are included in Figures S5-S8.

\subsection{Co-Immunoprecipitation Assay}

HEK293 and 5637 cells were seeded at the density of $3 \times 10^{6}$ cells / dish in $100 \mathrm{~mm}$ dishes (Euroclone, Pero, Italy) in DMEM or RPMI-1640 with 10\% FBS. The next day they were serum-starved (0.5\% FBS) for $18 \mathrm{~h}$ and later stimulated with $10 \%$ FBS for $15 \mathrm{~min}$ (S) or left unstimulated (NS). Co-immunoprecipitation assays were performed as previously described [40].

\subsection{Stress Media Composition and Assay}

To determine the average number of cells forming TNTs under several growth conditions, 5637 and HEK293 cells were cultured using: (I) High Serum Medium (HS) composed of DMEM medium supplemented with $10 \%$ FBS at normal pH 7.4 with $25 \mathrm{mM}$ glucose (usually referred to as standard culture medium); (II) Low Serum Medium (LS) composed of DMEM with 2.5\% FBS at normal pH 7.4 with $25 \mathrm{mM}$ glucose; (III) Low Serum Acidified Medium (LSA) composed of DMEM medium supplemented with $2.5 \%$ FBS at low $\mathrm{pH}$ (6.6) with $50 \mathrm{mM}$ glucose [19]; (IV) High Serum Medium with hydrogen peroxide ( $\mathrm{HS}+\mathrm{H}_{2} \mathrm{O}_{2}$ ) composed of DMEM with $10 \%$ FBS at normal $\mathrm{pH} 7.4$ with $25 \mathrm{mM}$ glucose and $100 \mu \mathrm{M} \mathrm{H}_{2} \mathrm{O}_{2} ;(\mathrm{V})$ Low Serum Medium with hydrogen peroxide $\left(\mathrm{LS}+\mathrm{H}_{2} \mathrm{O}_{2}\right)$ composed of DMEM with 2.5\% FBS at normal pH 7.4 with $25 \mathrm{mM}$ glucose and $100 \mu \mathrm{M} \mathrm{H}_{2} \mathrm{O}_{2}$ [49]. Cells grown in LSA, HS+ $\mathrm{H}_{2} \mathrm{O}_{2}$ and $\mathrm{LS}+\mathrm{H}_{2} \mathrm{O}_{2}$ media were first tested at different time points $(3,24,48$ and $72 \mathrm{~h}$; untreated controls are referred to as NT) to analyze cell morphology, membrane protrusion formation and loss of adherence; thus, ensuring that the generated stress did not result in cell death. LSA and $\mathrm{HS}+\mathrm{H}_{2} \mathrm{O}_{2}$ were also used to treat 5637 and HEK293 cells to evaluate RalGPS2 expression and p53 phosphorylation levels, respectively. Briefly, HEK293 and 5637 cells were plated in $100 \mathrm{~mm}$ dishes (Euroclone, Pero, Italy) in DMEM or RPMI-1640 medium supplemented with 10\% heat-inactivated FBS. The day after, the medium was replaced with LSA or $\mathrm{HS}+\mathrm{H}_{2} \mathrm{O}_{2}$, and, after $24 \mathrm{~h}$, the cells were lysed, and western blot analysis was performed as described above. Each experiment was performed in triplicate. Data were analyzed using GraphPadv6.0 software (San Diego, CA, USA) employing either ANOVA followed by Tukey's test for group comparison or Student's $t$-test. $p<0.05$ was considered statistically significant.

\subsection{RNA Interference}

For siRNA experiments, 5637 and HEK293 cells were plated at a density of $1 \times 10^{5}$ cells $/ \mathrm{mL}$ in 6-well plates (Euroclone, Pero, Italy) in RPMI-1640 or DMEM medium with $10 \%$ FBS. The next day, cells were co-transfected with pEGFP-C1 vector and $25 \mathrm{nmol}$ RalGPS2-specific Stealth siRNA, as previously described [40]. Then the medium was replaced with LSA or $\mathrm{HS}+\mathrm{H}_{2} \mathrm{O}_{2}$ and, after $24 \mathrm{~h}$, the cells were tested. Data were analyzed using GraphPadv6.0 software (San Diego, CA, USA) employing Student's $t$-test. $p<0.05$ was considered statistically significant. 


\subsection{TNTs Analysis under Pharmacologically Perturbed Conditions}

5637 and HEK293 cells were plated at a density of $1 \times 10^{5}$ cells $/ \mathrm{mL}$ on porcine gelatin pre-treated coverslips and transfected for RNA interference as described above or left un-transfected. The next day, the medium was replaced with LSA or $\mathrm{HS}+\mathrm{H}_{2} \mathrm{O}_{2}$, and after $24 \mathrm{~h}$, the cells were treated with or without $100 \mathrm{nM}$ Wortmannin (Sigma-Aldrich, St. Louis, MO, USA) or $10 \mu \mathrm{M}$ A6730 (Sigma-Aldrich, St. Louis, MO, USA) for $1 \mathrm{~h}$. After treatment, cells were stained with DiI (Sigma-Aldrich, St. Louis, MO, USA) to label cell membranes, according to the manufacturer's instructions. Cells were then fixed for 10 min with 3.7\% paraformaldehyde in phosphate-buffered saline (PBS). Fluorescence images were obtained with Leica TCSSP2 confocal microscope (Leica, Wetzlar, Germany) equipped with a $63 \times / 1.4$ NA Plan-Apochromat oil immersion objective. To quantitative determination, the percentage of cells forming nanotubes was assessed. About 200 cells, derived from different view fields of a plate, were analyzed for each experiment. The analysis was performed at the magnification described above. Experiments were performed in triplicate. Data were analyzed using GraphPadv6.0 software (San Diego, CA, USA) employing ANOVA followed by Tukey's test for group comparison. $p<0.05$ was considered statistically significant.

\section{Results}

\subsection{Tunneling Nanotubes Formation in Bladder Cancer Cell Lines}

Intercellular transfer of proteins [50,51], microRNA [17] and organelles [12,52] via tunneling nanotubes (TNTs) connecting long-distance cells promotes cell proliferation and invasion $[16,53]$. The type of TNTs formed by cells is affected by cell density, namely the distance and proximity between cells [54].

To characterize the bladder cancer microenvironment affected by TNTs, we analyzed a panel of six bladder cancer cell lines at different stages and grades, including RT4, RT112, 5637, HT1376, UMUC3 and J82 cell lines [48], which showed varying degrees of genetic complexity and different invasive properties. We assessed the number of cells forming tunneling nanotubes, the expression of proteins involved in tunneling nanotubes formation and the transfer of mitochondria via TNTs.

As shown in Figure 1, low-stage cell lines RT4 and RT112 do not exhibit TNTs, while medium and high-stage muscle invasive cell lines 5637, HT1376, UMUC-3 and J82, generate TNTs forming a complex network of cell-to-cell connections.

The percentage of cells forming TNTs in the different cell lines was assessed (Figure 2). Approximately $30 \%$ of cells in 5637 cell lines are able to make TNTs, while only approximately $20 \%$ of cells in UMUC- 3 and J82 cell lines produce them. HT1376 cell lines display the lowest percentage of cells forming TNTs, only $10 \%$. 

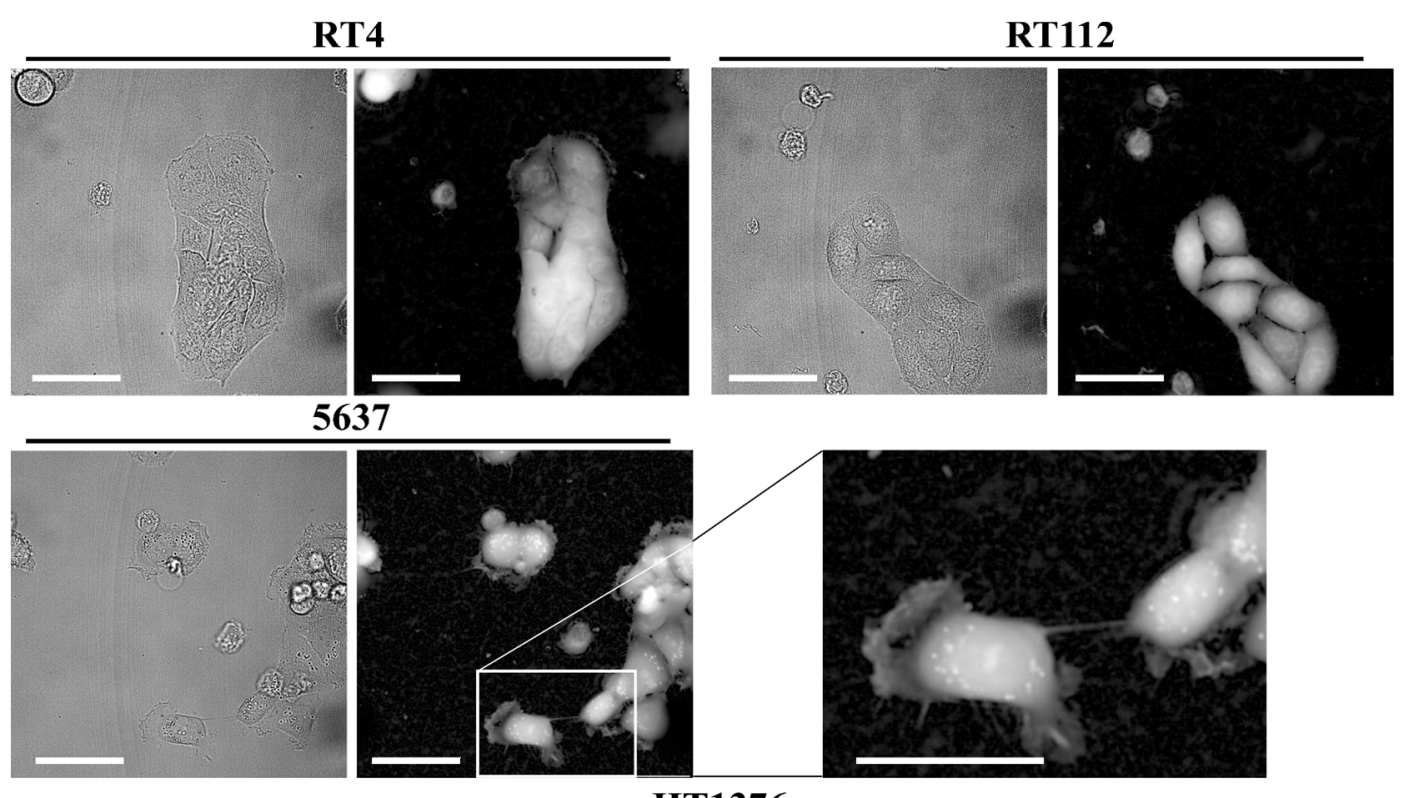

\section{HT1376}
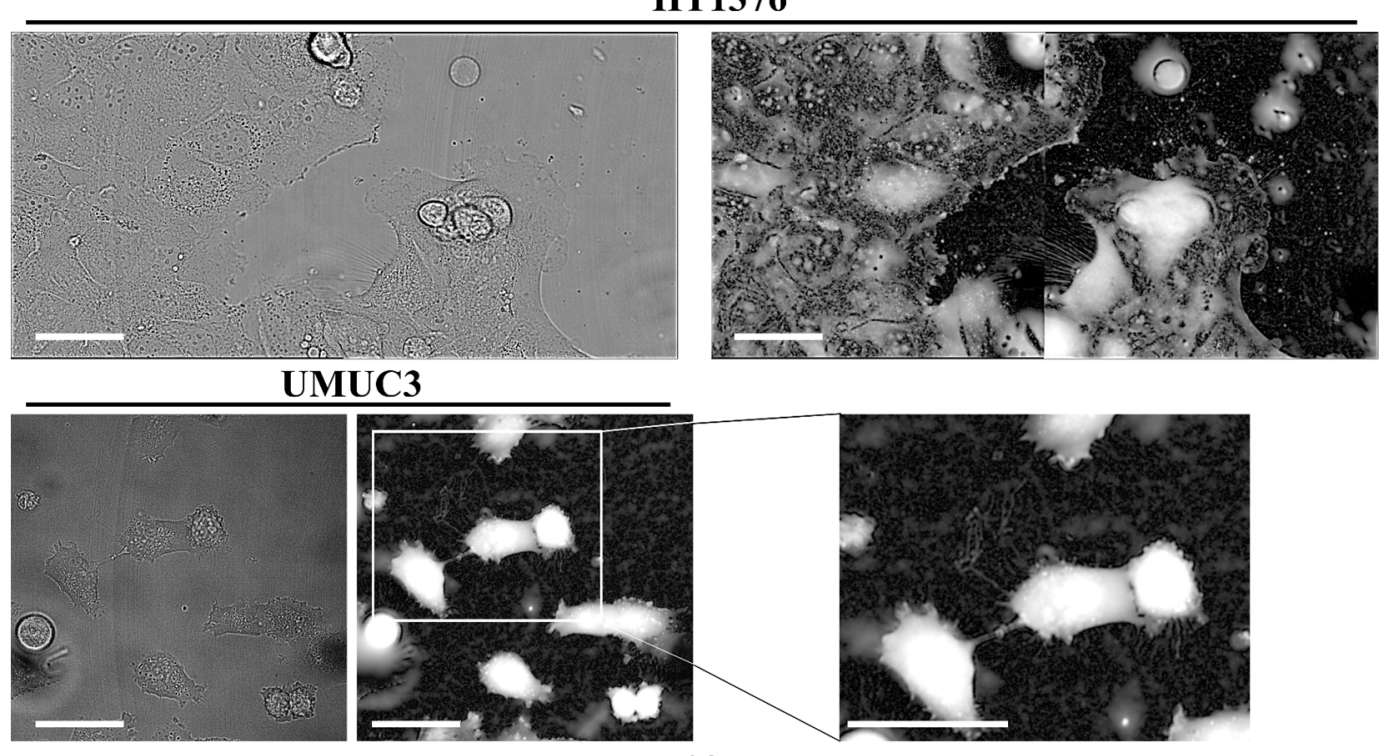

$\mathbf{J 8 2}$

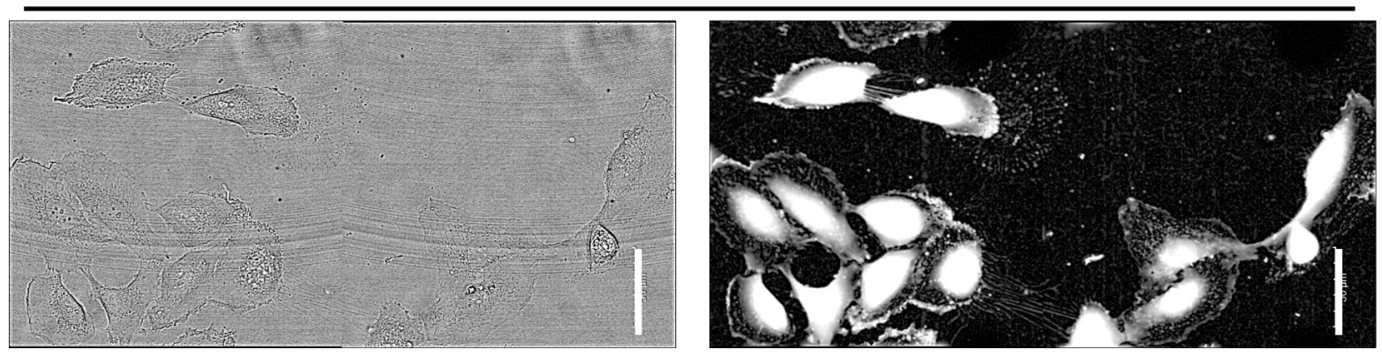

Figure 1. Tunneling nanotubes formation in bladder cancer cell lines. RT4, RT112, 5637, HT1376, UMUC-3 and J82 cells were plated at a density of $1 \times 10^{4}$ cells/well on CellCarrier Ultra 96-well microplates. After $24 \mathrm{~h}$, live cell images were acquired using Operetta CLS ${ }^{\mathrm{TM}}$ equipped with $63 \times$ immersion objective in brightfield (left panels) and Digital Phase Contrast (DPC) (right panels). Scale bar: $50 \mu \mathrm{m}$. Magnifications show TNTs. 


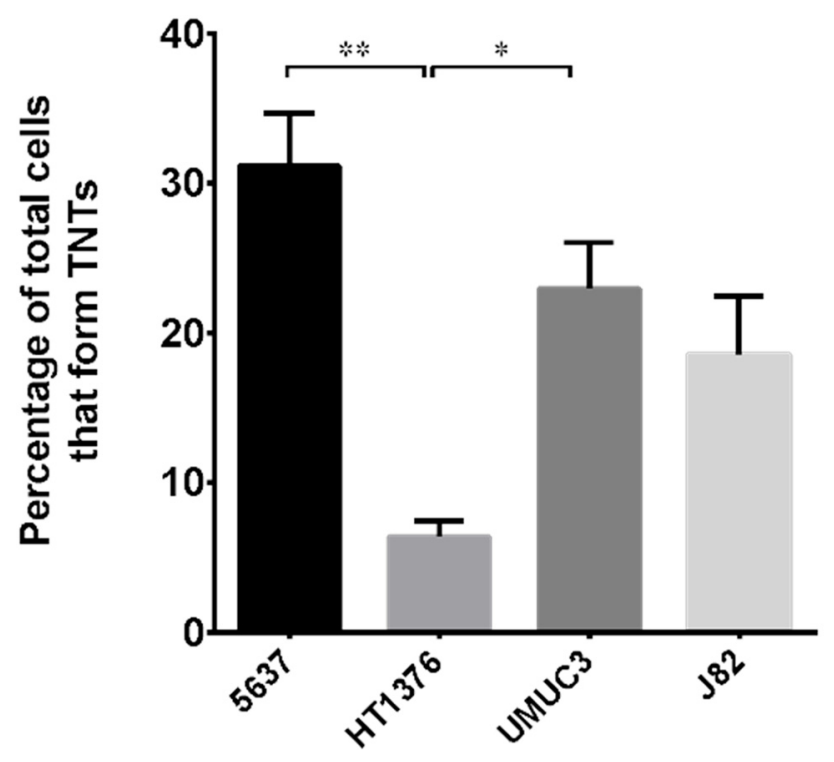

Figure 2. Percentage of cells forming TNTs in different bladder cancer cell lines. 5637, HT1376, UMUC-3 and J82 cell lines were plated as described in Figure 1, imaged by Operetta CLS ${ }^{\mathrm{TM}}$ and scored for the presence of nanotubes. At least 200 cells were analyzed per group in three independent experiments. Data are expressed as mean \pm S.E.M. from three independent experiments. Differences among groups were analyzed using a one-way analysis of variance (ANOVA) followed by Tukey's post hoc test. ${ }^{*} p<0.05,{ }^{* *} p<0.01$.

\subsection{Mitochondrial Transfer in Bladder Cancer Cell Lines through TNTs}

Tunneling Nanotubes (TNTs) are open-ended channels. In cancer, they drive the malignant phenotype [55], for example, allowing mitochondrial exchange [52,56].

To assess if TNTs observed in mid and high-stage bladder cancer cells show functional mitochondrial trafficking, we labeled cells with MitoTracker Green, a green-fluorescent mitochondrial dye that localizes to mitochondria regardless of mitochondrial membrane potential. We then performed live imaging analysis using an automated screening microscope, Operetta CLS ${ }^{\mathrm{TM}}$.

As shown in Figure 3 and Supplementary Figure S1, all cell lines considered were able to exchange mitochondria via TNTs. For most cell lines, the percentage of cells that transferred mitochondria was under $10 \%$, with the exception of UMUC-3 cells [57], which have the most invasive phenotype, reaching $30 \%$ (Figure 4). Furthermore, to understand if mitochondria transferred via tunneling nanotubes were functional, cells were labeled with MitoTracker Green in combination with Tetramethylrhodamine, Ethyl Ester, Perchlorate (TMRE). TMRE is a red-orange fluorescent dye that is quickly sequestered by active mitochondria. No correlation between mitochondrial trafficking and functionality during transport was reported (Supplementary Figure S2). Our data show that bladder cancer cells can exchange both functional and non-functional mitochondria. 

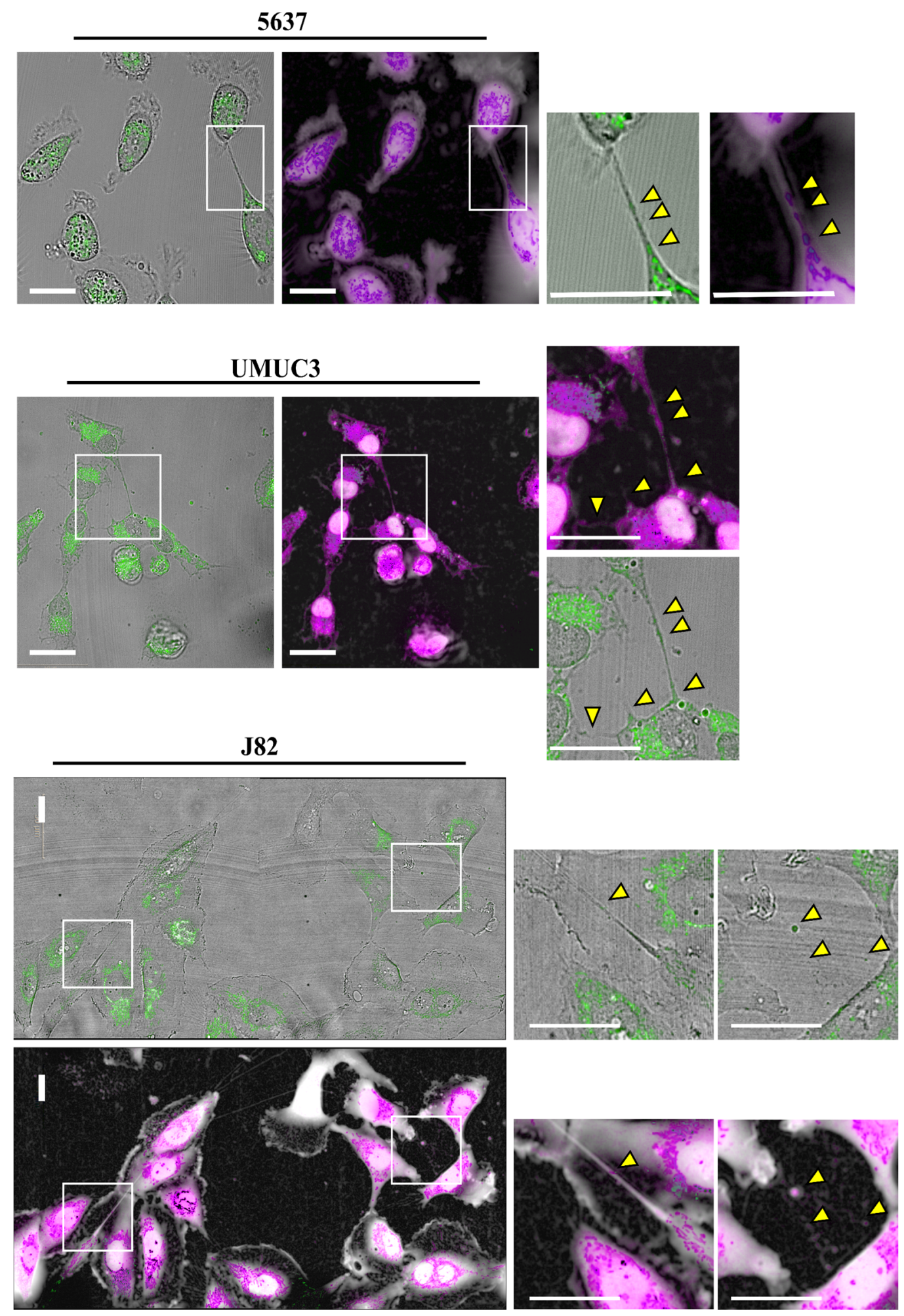

Figure 3. Mitochondrial transfer via TNTs in bladder cancer cell lines. 5637, UMUC-3 and J82 cells were plated at a density of $1 \times 10^{4}$ cells/well on Cell Imaging 24-well Plates. After $24 \mathrm{~h}$, cells were stained with MitoTracker ${ }^{\mathrm{TM}}$ Green and live cell images were acquired using Operetta CLS ${ }^{\mathrm{TM}}$, equipped with $63 \times$ immersion objective in brightfield, DPC and fluorescence, to detect MitoTracker. Scale bar: $20 \mu \mathrm{m}$. Yellow triangles indicate mitochondria. Magnified views of mitochondria inside nanotubes are shown. 


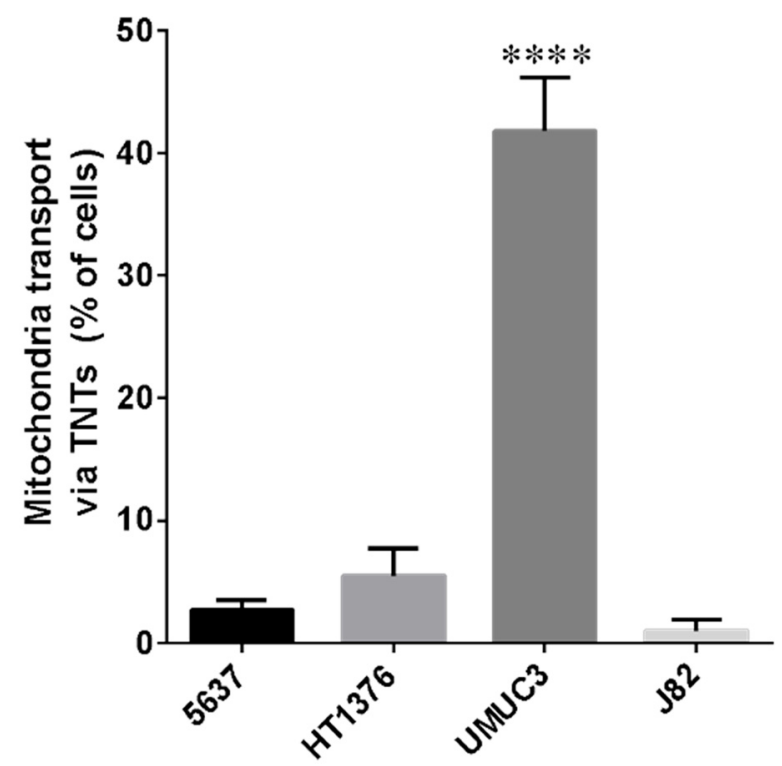

Figure 4. Percentage of bladder cancer cells able to exchange mitochondria via TNTs. 5637, HT1376, UMUC-3 and J82 cells were plated and stained as described in Figure 3, imaged by Operetta CLS ${ }^{\mathrm{TM}}$ and scored for the presence of mitochondria inside TNTs. At least 200 cells were analyzed per group in three independent experiments. Data are expressed as mean \pm S.E.M. from three independent experiments. Differences among groups were tested for significance by the one-way analysis of variance (ANOVA) followed by Tukey's post hoc test. ${ }^{* * *} p<0.0001$ indicated significance compared to all the other groups.

Since TNTs were not detected in RT4 and RT112 cell lines, we did not analyze them in this experiment. Our data demonstrate that nanotubes generated by bladder cancer cells are functional.

\subsection{Expression of Proteins Involved in Tunneling Nanotubes Formation in Bladder Cancer Cells}

RalA GTPase is involved, together with the exocyst complex, in tunneling nanotubes formation [44]. It has been previously demonstrated that RalGPS GEFs have a prominent role in RalA activation in 5637 bladder cancer cell lines. Indeed, on the one hand, silencing RalGPS2 inhibits endogenous nanotubes formation; on the other hand, its over-expression, or the downregulation of RalGDS family proteins caused by the expression of the dominantnegative mutant H-RasV12S35, which specifically activate Raf and not RalGDS family of GEFs [58], increases the length and the number of TNTs [40].

To study the expression of RalA GTPase and RalGPS2 in the six bladder cancer cell lines previously considered, western blot analyzes were performed. GAPDH was used as the loading control to normalize and quantify protein amount. RalGPS2 is expressed in all cell lines, though very low levels of expression were detected in UMUC-3 and J82 cell lines (Figure 5A,B). Only in the 5637 cell line two isoforms of RalGPS2 were detected. RalA was expressed at a high level only in 5637 and HT1376 cell lines (Figure 5A,C).

The 5637 cell line showed the highest percentage of nanotubes-forming cells and the highest expression of RalA and RalGPS2. Consequently, they were selected as a model to perform further analyzes aimed at studying the TNTs microenvironment in bladder cancer cells. 
$\mathbf{A}$

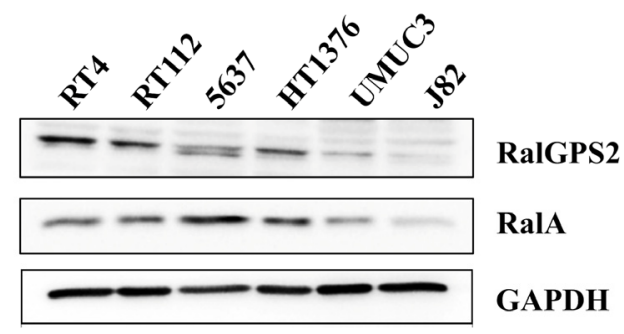

B

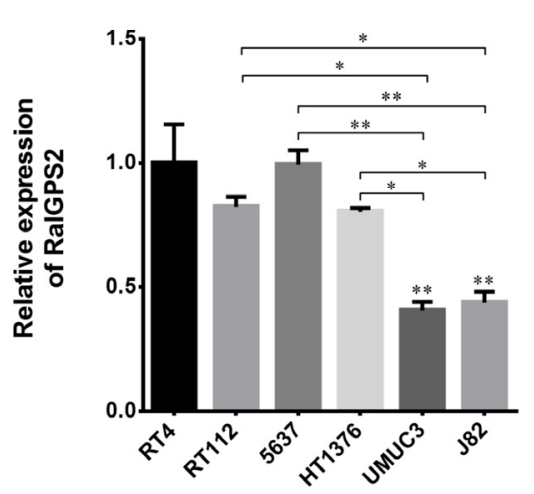

C

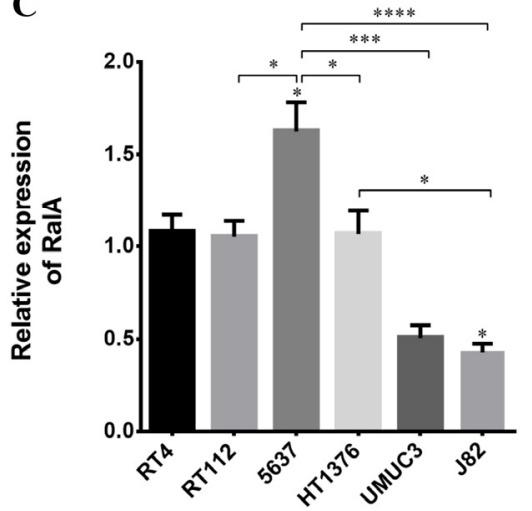

Figure 5. RalGPS2 and RalA expression in bladder cancer cell lines. RT4, RT112, 5637, HT1376, UMUC-3 and J82 cell lysates were separated on SDS-PAGE and blotted to nitrocellulose membrane; blots were probed with anti-RalA or anti-RalGPS2 or anti-GAPDH antibodies. GAPDH was used as a loading control. Panel (A): representative Western blot results are shown. Panel (B): histograms relative to the quantification of RalGPS2 bands. Panel (C): histograms relative to the quantification of RalA bands. Data are expressed as mean \pm S.E.M. from three independent experiments. Differences among groups were analyzed using a one-way analysis of variance (ANOVA) followed by Tukey's post hoc test. ${ }^{*} p<0.05,{ }^{* *} p<0.01,{ }^{* * *} p<0.001,{ }^{* * * *} p<0.0001$.

\subsection{RalA and LST1 Are Transferred via TNTs in 5637 Cells}

The transfer of proteins through TNTs is a well-documented mechanism [50,51]. Since 5637 cells showed functional TNTs able to transfer mitochondria, their ability to transfer RalA GTPase and RalGPS2 was assessed. 5637 cells were transfected either with RalAmCherry or RalGPS2-GFP constructs, and the day after transfection, live imaging analysis was performed using Operetta CLSTM. RalA GTPase pass through TNTs, while RalGPS2 was not detectable in tunneling nanotubes (Figure $6 \mathrm{~A}, \mathrm{C}$ and Videos S1 and S2).

Another important molecule involved in TNTs formation is leukocyte-specific transcript 1 (LST1), a well-established binding partner of RalA and RalGPS2 [36]. To investigate if LST1 is transported via tunneling nanotubes in our model, 5637 cells were transfected with LST1-mCherry construct and live image analysis was performed, as described above. As shown in Figure 6B, LST1 was effectively transferred via TNTs in 5637 cells (Video S3). 


\section{A RalA}

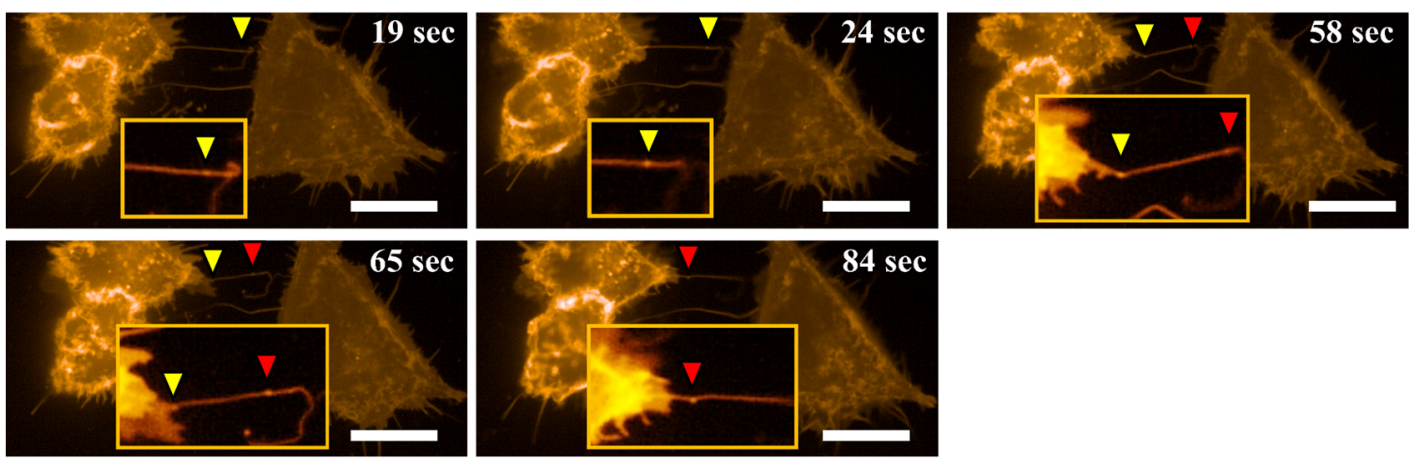

\section{B LST1}
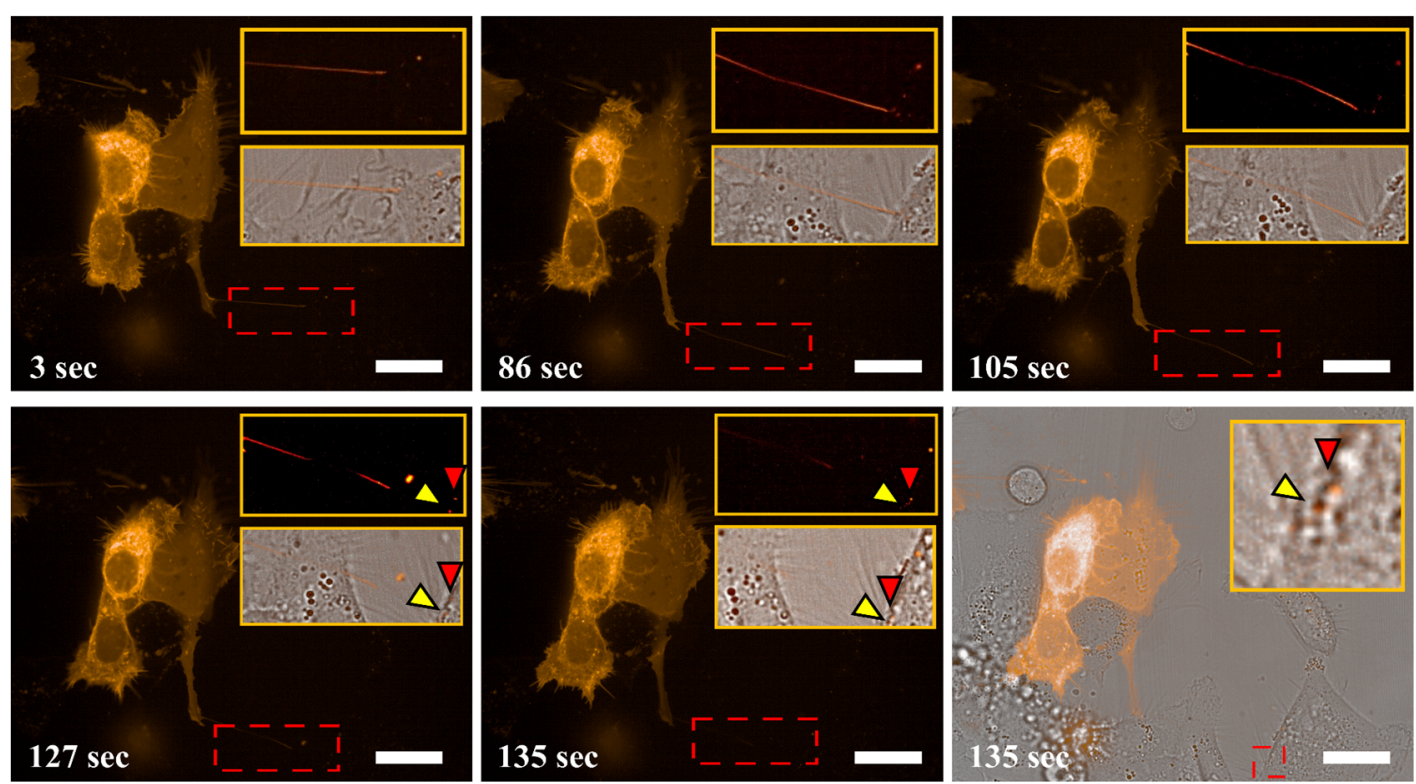

\section{RalGPS2}
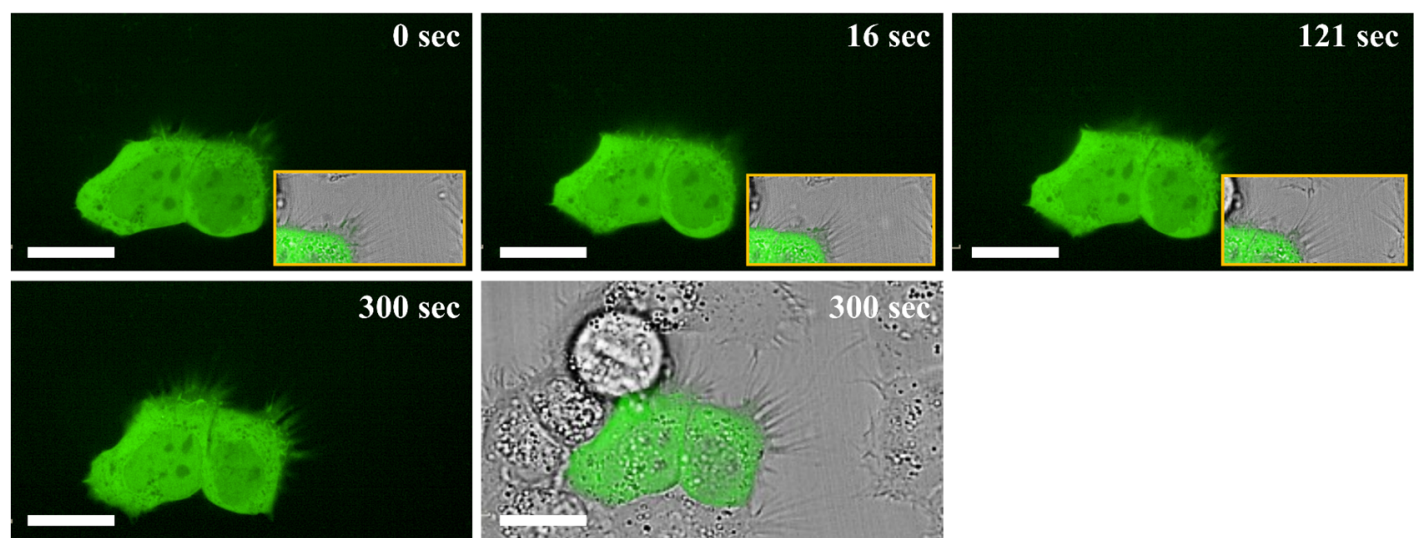

Figure 6. Intracellular transport via TNTs of mobile RalA and LST1 in 5637 cells. 5637 cells were seeded at the concentration of $1 \times 10^{4}$ cells/well on Cell Imaging 24-well Plates. After $24 \mathrm{~h}$, cells were transfected with (A) mCherry-RalA or (B) mCherry-LST1 or (C) pEGFP-RalGPS2; the day after, time-lapse imaging was performed using Operetta CLS ${ }^{\mathrm{TM}}$ equipped with $63 \times$ immersion objective. Scale bar: $20 \mu \mathrm{m}$. Yellow and red triangles indicate transfected proteins transferred from one cell to another one. Magnified views of vesicles containing transfected proteins inside nanotubes are shown. 


\subsection{Stress Conditions Promote TNTs formation in HEK293 and 5637 Cells}

Wang et al., in 2011, demonstrated that cells in induced stress conditions produce more nanotubes compared to cells cultured in physiological conditions [49]. Specifically, Wang et al. demonstrated that treatment with $\mathrm{H}_{2} \mathrm{O}_{2}$ and serum depletion induces TNTs formation in astrocytes and neurons. TNTs formation is thus induced by different cellular stressors, such as nutrient deprivation, low $\mathrm{pH}$, hypoxia and oxidative stress [59].

To assess which stress condition, among low-serum, acidification or oxidative insult, could promote TNTs formation in 5637 and HEK293 cells, we tested different culture media (Materials and Methods) mimicking the diverse types of stress.

HEK293 cells were choosen as a cellular model. to validate our findings in other cells of the urinary system. In this cell line, RalGPS2 is expressed and able to activate RalA GTPase, as our group previously demonstrated [45]. In all culture conditions tested, we assessed cell responses, such as morphology changes and membrane protrusions formation.

HEK293 and 5637 cells are normally grown in DMEM and RPMI-basedmedium, respectively, containing $25 \mathrm{mM}$ glucose, $2 \mathrm{mM}$ L-Glutamine and 10\% FBS, and the $\mathrm{pH}$ of the culture medium is buffered to 7.4 .

To induce stress conditions, we decided to use two media previously described in the literature [19,49]. The first one, a low-pH medium, referred to as LSA, is an Acidified hyperglycemic Low-Serum medium ( $\mathrm{pH}$ 6.6, $50 \mathrm{mM}$ glucose, 2.5\% foetal bovine serum) that boosts the invasive potential of cancer cells (Supplementary Figure S3); the second, here referred to as $\mathrm{H}_{2} \mathrm{O}_{2}$ (tested in two different serum conditions: High Serum (HS containing $10 \%$ foetal bovine serum) or Low Serum (LS containing $2.5 \%$ foetal bovine serum)), is an oxidative stress medium (DMEM with $10 \%$ or $2.5 \%$ FBS at normal $\mathrm{pH}$ 7.4 with $25 \mathrm{mM}$ glucose and $100 \mu \mathrm{M} \mathrm{H}_{2} \mathrm{O}_{2}$ ) that induces cellular insult and leads to p53 activation (Figure S4). Since maintaining cells in low serum is a well-known TNTs inducer $[19,60]$, we decided to test this experimental setting in combination with $\mathrm{H}_{2} \mathrm{O}_{2}$ to enhance nanotubes generation.

As shown in Supplementary Figure S3, the formation of TNTs increased in 5637 cells $24 \mathrm{~h}$ after LSA medium addition, while HEK293 cells died after $180 \mathrm{~min}$.

The $\mathrm{H}_{2} \mathrm{O}_{2}$-containing medium caused no effect in 5637 cells. Indeed, even after $72 \mathrm{~h}$ of exposure to $\mathrm{H}_{2} \mathrm{O}_{2}$ medium, the cells continued to grow, and no morphological changes were visible, both in the HS and LS media (Figure S4).

HEK293 cells responded to oxidative stress producing a higher number of TNTs compared to control, already at $24 \mathrm{~h}$ in HS medium, while in the LS medium, the cells showed signs of suffering and no TNTs was detected. At $72 \mathrm{~h}$ in the HS medium, TNTs increased, but cells showed morphological differences: they became rounded and partially detached from the substratum. Moreover, in the LS medium, cells died, indicating that the stress level was too high.

Therefore, our results demonstrate that TNTs production in 5637 and HEK293 cells is increased by acidification and oxidative stress, respectively.

To confirm the data obtained by the inverted microscope, we analyzed TNTs formation by confocal microscopy, comparing cells cultured in HS and LS media ( $10 \%$ or $2.5 \%$ FBS) to cells in an appropriate stress medium.

In the HS medium, 5637 cells showed a higher percentage ( 30\%) of cells forming TNTs than the HEK293 cell line ( $10 \%)$ (Figure 7B,D). Furthermore, there was no difference in the percentage of HEK293 cells forming TNTs in HS or LS media. Instead, 5637 cells cultured in LS reached $50 \%$ of cells displaying TNTs. Thus, low-serum conditions represent a stressful state for 5637 cells, while HEK293 cells are not affected.

As shown in Figure 7, LSA and $\mathrm{HS}+\mathrm{H}_{2} \mathrm{O}_{2}$ media increased the percentage of cells forming TNTs up to $80 \%$, confirming the data obtained by inverted microscope. 


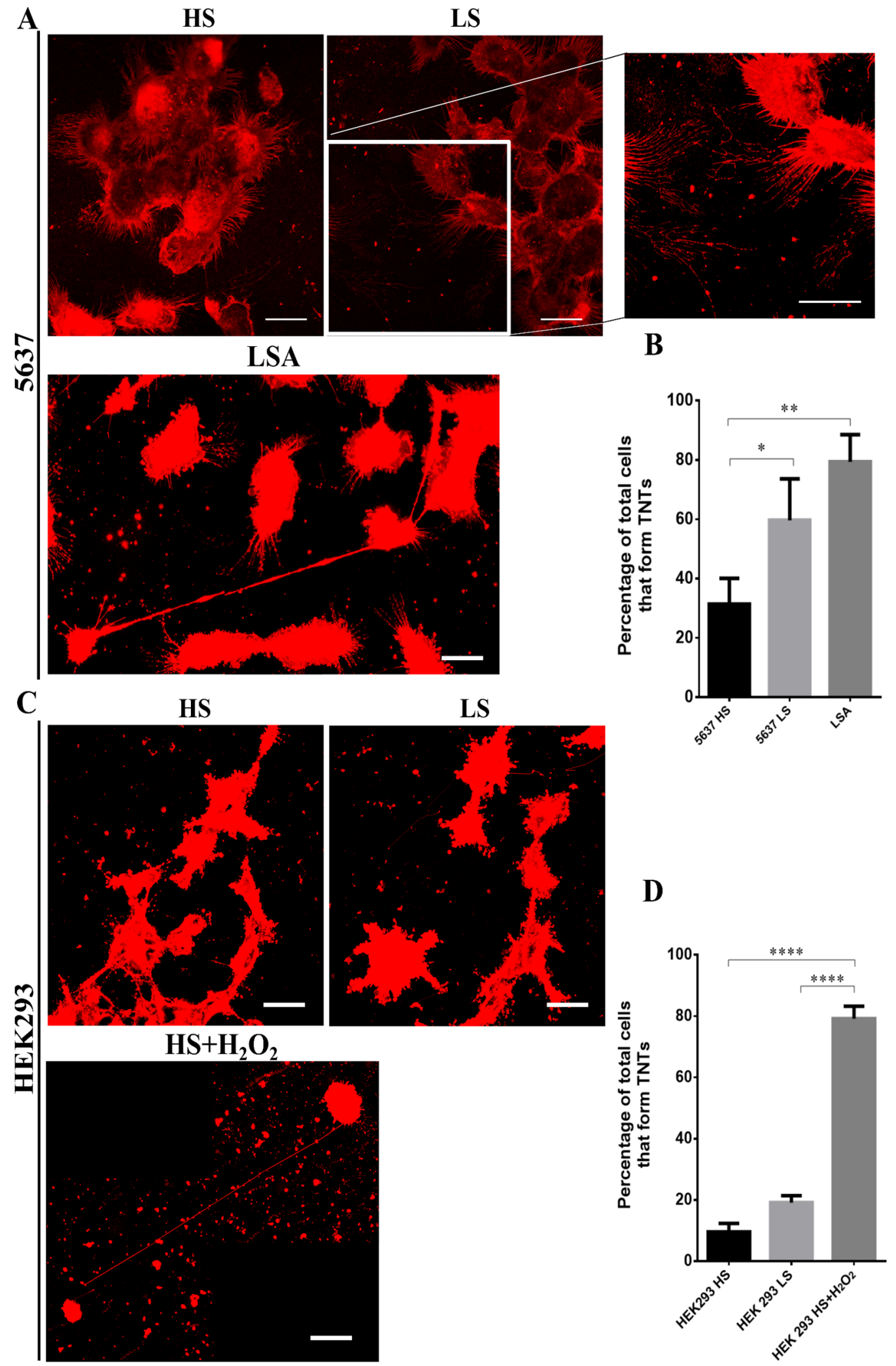

Figure 7. Effect of stress conditions on TNTs formation. (A) 5637 and (C) HEK293 cells were plated at a density of $1 \times 10^{5}$ cells $/ \mathrm{mL}$ on porcine gelatin pre-treated coverslips. The next day, cells were placed under several growth conditions as indicated in each panel and, after $24 \mathrm{~h}$, were stained with the membrane dye DiI, fixed, permeabilized and imaged via confocal microscopy. Scale bar: $20 \mu \mathrm{m}$. Magnified views of nanotubes are shown. HS ( $25 \mathrm{mM}$ glucose, 10\% FBS, pH 7.4) = High Serum; 
LS (25 mM glucose, 2.5\% FBS, pH 7.4) = Low Serum; LSA (50 mM glucose, 2.5\% FBS, pH 6.6) = Low Serum Acidified; $\mathrm{HS}+\mathrm{H}_{2} \mathrm{O}_{2}\left(25 \mathrm{mM}\right.$ glucose, $10 \%$ FBS, pH 7.4, $\left.100 \mu \mathrm{M} \mathrm{H}_{2} \mathrm{O}_{2}\right)$. Histograms relative to the percentage of cells forming TNTs in (B) 5637 and (D) HEK293 cells. At least 200 cells were analyzed per group in three independent experiments. Data are expressed as mean \pm S.E.M. from three independent experiments. Differences among groups were analyzed using the one-way analysis of variance (ANOVA) followed by Tukey's post hoc test. ${ }^{*} p<0.05,{ }^{* *} p<0.01,{ }^{* * * *} p<0.0001$.

\subsection{RalGPS2 Is Crucial to TNTs Formation Also in Stress Conditions in 5637 and HEK293 Cells}

We have previously demonstrated that RalGPS2 is involved in the formation of TNTs and that the overexpression of RalGPS2 markedly increases the number and length of nanotubes $[40,61]$.

Furthermore, we have demonstrated that the knock-down of RalGPS2 using siRNA leads to a strong reduction of TNTs formation in 5637 cells [40]. Therefore, we decided to test the effect of RalGPS2 depletion combined with TNTs induction promoted by stress media (LSA and $\mathrm{HS}+\mathrm{H}_{2} \mathrm{O}_{2}$ ).

After transfection with the specific siRNA for RalGPS2, cells were cultured for $24 \mathrm{~h}$ in LSA and $\mathrm{HS}+\mathrm{H}_{2} \mathrm{O}_{2}$ media.

RalGPS2 silencing caused a strong reduction in the percentage of cells producing TNTs in both cell lines (Figure 8). These data suggest that RalGPS2 has a crucial role in TNTs formation.

Subsequently, to further evaluate if the increase in TNTs formation observed under stress conditions was related to an enhancement in RalGPS2 expression, we performed western blot assays after $24 \mathrm{~h}$ from stress medium administration. Cells in HS medium were used as control. The experiment was carried out using a specific stress medium for each cell line. As it is shown in Figure 9A,B that RalGPS2 expression increased in both cell lines at $24 \mathrm{~h}$ after exposure to stress conditions.

The p53 tumor suppressor has a vital role in regulating cancer cell death, cell cycle arrest, apoptosis, senescence and DNA repair [62]. Moreover, p53 responds to various stress signals promoting the transcription of a series of genes and is critical for TNTs formation in astrocytes under stress conditions [49].

To analyze p53 activation (through assessment of its phosphorylation status), HEK293 and 5637 cells were cultured in specific stress media, and equal amounts of total protein extracts were loaded onto $8 \%$ denaturing polyacrylamide gel. Active p53 was assessed by western blot assays, using a specific antibody that detects phosphorylation occurring on Threonine 155 residue of p53. For both cell lines, the active-p53 expression did not change (Figure 9C,D). In conclusion, data obtained using confocal microscopy and western blot assays show that an increase in TNTs formation is related to an enhancement in RalGPS2 expression, but not to a change in the levels of phospho-p53 (p53 P). 


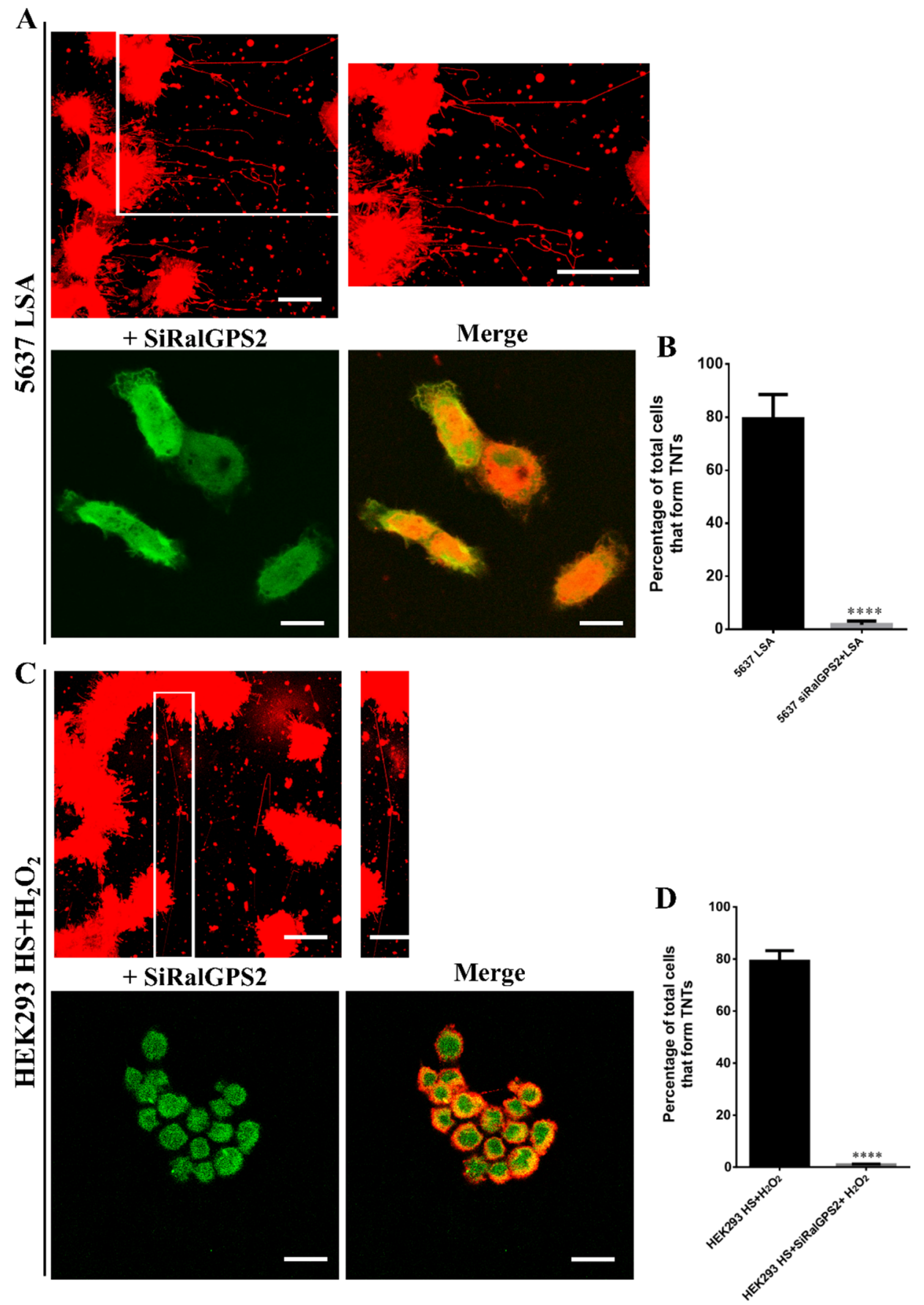

Figure 8. Effect of RalGPS2 depletion under stress conditions on TNTs formation. (A) 5637 and (C) HEK293 cells were plated at a density of $1 \times 10^{5}$ cells $/ \mathrm{mL}$ on porcine gelatin pre-treated coverslips. The next day cells were transfected with the specific siRalGPS2 (green), placed under several growth conditions, as indicated in each panel, and, after $24 \mathrm{~h}$, were stained with the membrane dye DiI (red), fixed, permeabilized and imaged via confocal microscopy. Scale bar: $20 \mu \mathrm{m}$. Magnified views of nanotubes are shown. LSA ( $50 \mathrm{mM}$ glucose, 2.5\% FBS, pH 6.6) = Low Serum Acidified; $\mathrm{HS}+\mathrm{H}_{2} \mathrm{O}_{2}$ (25 mM glucose, 10\% FBS, pH 7.4, $100 \mu \mathrm{M} \mathrm{H}_{2} \mathrm{O}_{2}$ ). Histograms relative to the percentage of cells forming TNTs in (B) 5637 and (D) HEK293 cells. At least 200 cells were analyzed per group in three independent experiments. Data are expressed as mean \pm S.E.M. from three independent experiments. Differences among groups were tested for significance by Student's t-test. ${ }^{* * *} p<0.0001$. 
A
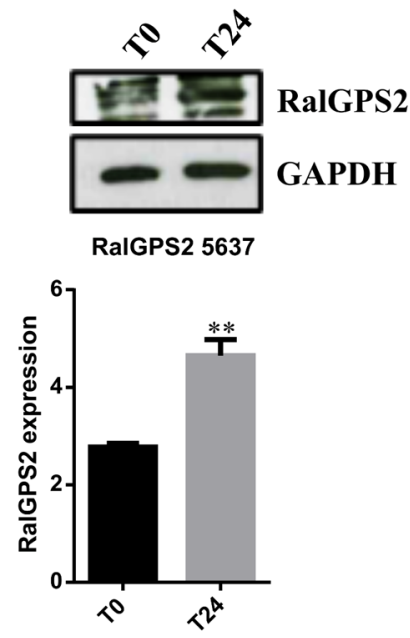

C

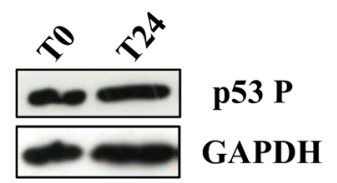

p53 P 5637

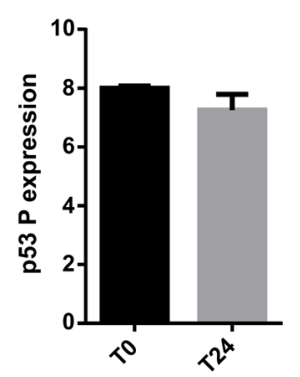

B
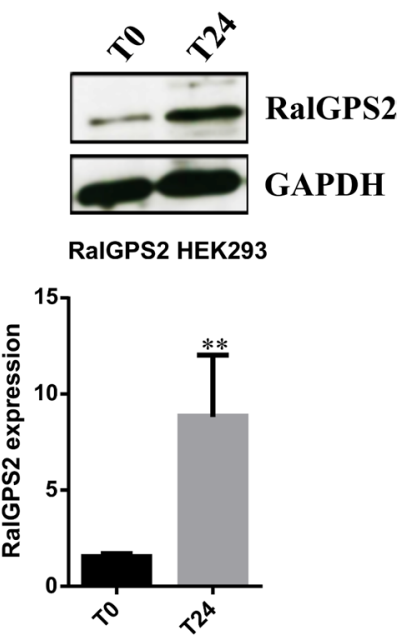

D

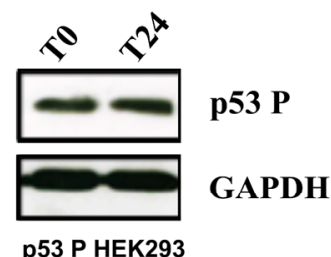

p53 P HEK293

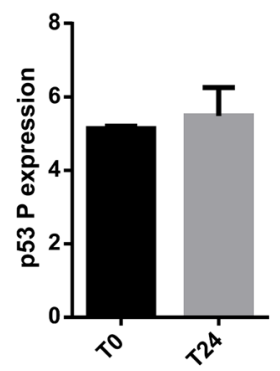

Figure 9. Stress conditions boost RalGPS2 expression in 5637 and HEK293 cells. 5637 and HEK293 cell lysates were separated on SDS-PAGE and blotted to nitrocellulose membrane; blots were probed with anti-RalGPS2 or anti-phospho p53 (p53 P) or anti-GAPDH antibodies. GAPDH was used to normalize sample loading. Panels (A,C): expression of RalGPS2 and p53 P in 5637 cells treated with LSA medium for $24 \mathrm{~h}$. The panels show representative western blot results and the quantification of (A) RalGPS2 or (C) p53 P expression. Panels (B,D): expression of RalGPS2 and p53 P in HEK293 cells treated with $\mathrm{HS}+\mathrm{H}_{2} \mathrm{O}_{2}$ medium for $24 \mathrm{~h}$. The panels show representative western blot results and the graphical representation of (B) RalGPS2 or (D) p53 P expression. Data are expressed as mean \pm S.E.M. from three independent experiments. Differences among groups were analyzed using Student's $t$-test. ** $p<0.01$.

\subsection{PI3K and Akt Inhibition Reduces TNTs Formation in HEK293 and 5637 Cells}

Upregulation of the Akt/PI3K/mTOR signaling pathway by stress conditions is a well-documented mechanism involved in nanotubes formation [19]. In fact, under stressful conditions, p53 up-regulates EGFR and TNF $\alpha$-induced protein 2 (TNF $\alpha$ IP2, also known as $\mathrm{M}-\mathrm{Sec}$ ), which in turn activates Akt/PI3K/mTOR and RalA-exocyst pathways, respectively. Both pathways are necessary for TNTs development [49]. D'Aloia et al., in 2018, showed that RalGPS2 affects Akt activation in 5637 cells [40]. Therefore, we decided to further investigate, both in HEK293 and 5637 cells, whether RalGPS2 interacts with Akt and the protein kinase responsible for Akt activation, pyruvate dehydrogenase kinase 1 (PDK1) [40].

Using co-immunoprecipitation assays, we demonstrated that both active/phosphorylated (Akt P) and total Akt and PDK1 co-immunoprecipitated with RalGPS2. Experiments were performed using serum-starved cells ( $0.5 \%$ FBS), following either 15 min of serum stimula- 
tion ( $\mathrm{S}=$ stimulated with $10 \% \mathrm{FBS}$ ), or as control, leaving them unstimulated (NS = not stimulated) (Figure 10). With our experiments, we could demonstrate that RalGPS2 is able to form a complex with Akt and PDK1, as tested in HEK293 and 5637 cell lines. Within this complex, p53 P and TNF $\alpha$ IP2 are also present.

A

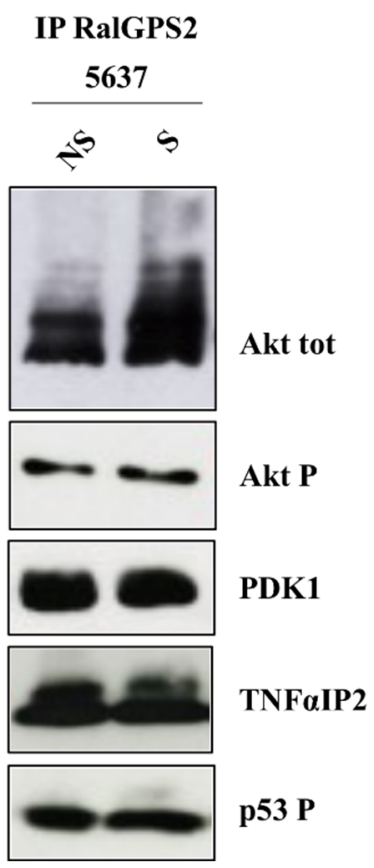

B

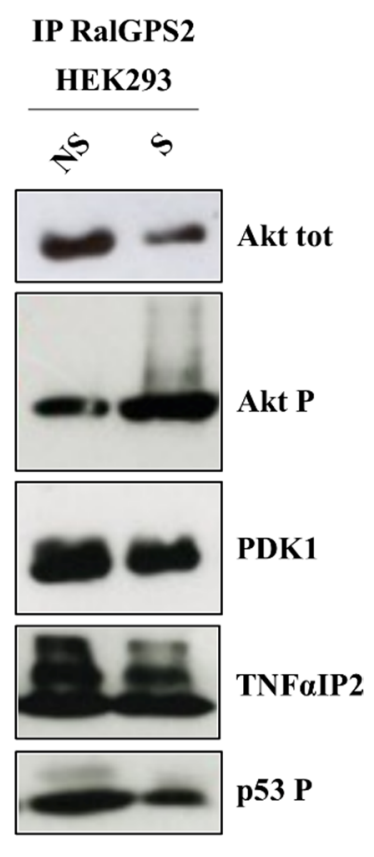

Figure 10. RalGPS2 interacts with Akt, PDK1, TNF $\alpha$ IP2 and p53 P in 5637 and HEK293 cells. (A) 5637 and (B) HEK293 cells were plated in $100 \mathrm{~mm}$ dishes and the day after were first serum-starved for $18 \mathrm{~h}$ and then stimulated with 10\% FBS for $15 \mathrm{~min}$ (S) or left unstimulated (NS). Subsequently, immunoprecipitation (IP) with anti-RalGPS2 antibodies was performed, as indicated in each panel. Immunoprecipitates were assessed for the presence of total Akt (Akt tot), phospho-Akt (Akt P), PDK1, TNF $\alpha$ IP2 and phospho-p53 (p53 P). Three independent experiments were performed.

To elucidate the mechanisms and upstream signals that mediate RalGPS2 activation, we studied which consequences might have the inhibition of proteins involved in the complex activation. Since the PH domain of RalGPS2 binds to phosphatidylinositol 4,5 bisphosphate (PIP2) [45], a PI3K product, we decided to test the effect of wortmannin, a PI3K inhibitor. HEK293 and 5637 cells were grown in the specific stress medium for $24 \mathrm{~h}$; then, wortmannin was added for $1 \mathrm{~h}$. Cells were stained with the lipophilic membrane stain DiI and assessed for TNTs presence.

PI3K inhibition caused a decrease in the number of cells with TNTs, resulting in a percentage of cells having TNTs similar to the ones observed in cells grown in HS medium (Figure 11). Furthermore, PI3K inhibition in HEK293 cells, similarly to RalGPS2 silencing, diminished the proportion of cells forming TNTs, while in 5637 cells, RalGPS2 depletion had a more pronounced effect than PI3K blockage.

Subsequently, we decided to test the effect of A6730, an Akt inhibitor, on tunneling nanotubes formation.

The number of cells forming TNTs was reduced in both cell lines. In the HEK293 cell line, a lower percentage of TNTs-displaying cells was observed, though the number was higher compared to cells in the control condition and under treatment with wortmannin. Taken together, our results suggest that although Akt is important in TNTs generation, it is not essential in this process. Conversely, the presence of an active RalGPS2 pathway is crucial. 


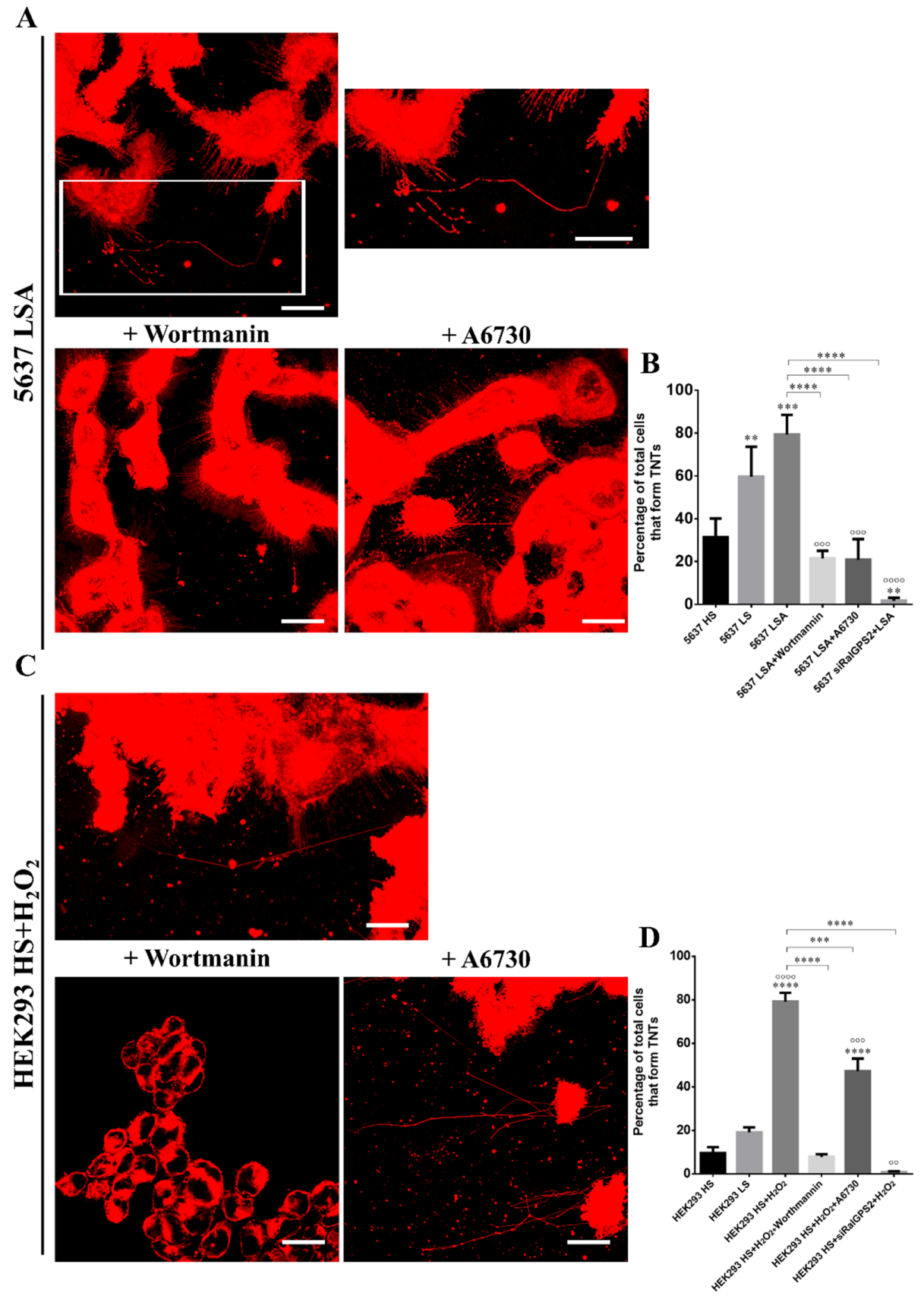

Figure 11. Effect of PI3K and Akt inhibition under stress conditions on TNTs formation. (A) 5637 and (C) HEK293 cells were plated at a density of $1 \times 10^{5}$ cells $/ \mathrm{mL}$ on porcine gelatin pre-treated coverslips. The next day the medium was replaced with LSA or $\mathrm{HS}+\mathrm{H}_{2} \mathrm{O}_{2}$, respectively, and $24 \mathrm{~h}$ later, the cells were treated with or without $100 \mathrm{nM}$ Wortmannin or $10 \mu \mathrm{M}$ A6730, as indicated in each panel. After $1 \mathrm{~h}$ of treatment, cells were stained with the membrane dye DiI, fixed, permeabilized and imaged via confocal microscopy. Scale bar: $20 \mu \mathrm{m}$. Magnified views of nanotubes are shown. Histograms relative to the percentage of cells forming TNTs in (B) 5637 and (D) HEK293 cells. At least 200 cells were analyzed per group in three independent experiments. Data are expressed as mean \pm S.E.M. from three independent experiments. Differences among groups were tested for significance by the one-way analysis of variance (ANOVA) followed by Tukey's post hoc test. ${ }^{* *} p<0.01,{ }^{* * *} p<0.001$, **** $p<0.0001 .{ }^{\circ 0} p<0.01,{ }^{\circ 00} p<0.001,{ }^{\circ 000} p<0.0001$ significance compared to LS. HS ( $25 \mathrm{mM}$ glucose, 10\% FBS, pH 7.4) = High Serum; LS (25 mM glucose, 2.5\% FBS, pH 7.4) = Low Serum; LSA $\left(50 \mathrm{mM}\right.$ glucose, $2.5 \%$ FBS, $\mathrm{pH}$ 6.6) = Low Serum Acidified; $\mathrm{HS}+\mathrm{H}_{2} \mathrm{O}_{2}(25 \mathrm{mM}$ glucose, $10 \% \mathrm{FBS}, \mathrm{pH}$ 7.4, $100 \mu \mathrm{M} \mathrm{H}_{2} \mathrm{O}_{2}$ ). 
In the 5637 cell line, the percentage of cells forming nanotubes is comparable to the one resulting upon PI3K inhibition, indicating the Akt pathway plays a fundamental role in the process.

\subsection{RalGPS2 Forms a Complex with LST1, RalA and Sec5 in HEK293 Cells}

In the 5637 cell line, RalGPS2 forms a complex with RalA, Sec5 and LST1 that is required for TNTs formation, as we previously demonstrated [36,40]. Here, we evaluated if this complex is also present in HEK293 cells. Co-immunoprecipitation assays (RalGPS2, LST1 and Sec5) were performed on serum-starved (0.5\%FBS) HEK293 cells under serumstimulated (S) or unstimulated (NS) conditions. We found that, also in HEK293 cells, RalA co-immunoprecipitated with RalGPS2, Sec5 and LST1 and these three proteins interacted with each other (Figure 12). Furthermore, no difference was observed between the stimulated or unstimulated conditions, and in the immunoprecipitation complex, we found both the trimeric and the monomeric form of LST1, as it has been shown for 5637 cells in D'Aloia et al., 2018 [40]. Thus, the complex first identified in 5637 bladder cancer cells is also present in other cell types, such as HEK293.

A

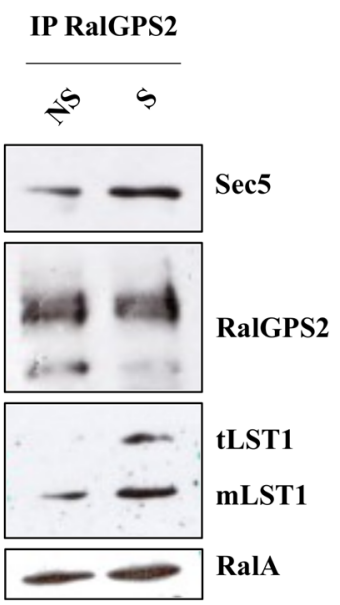

B

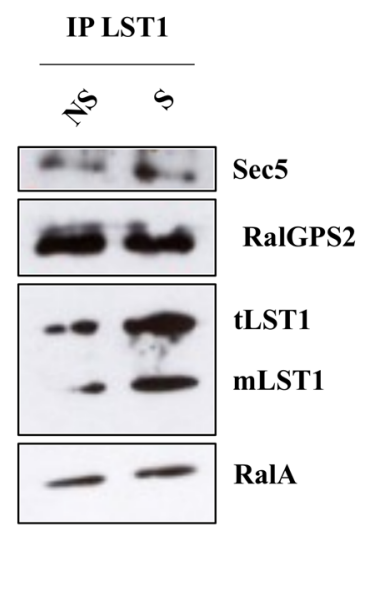

C

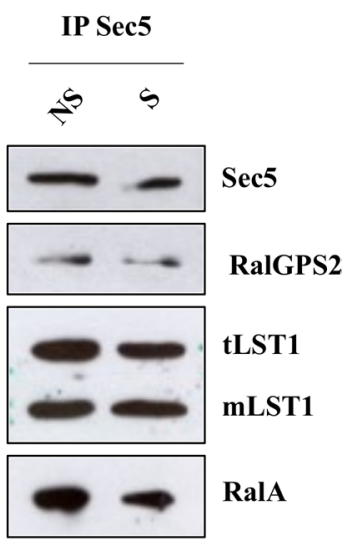

Figure 12. RalGPS2 interacts with RalA, LST1 and Sec5 in HEK293 cells. HEK293 cells were plated in $100 \mathrm{~mm}$ dishes, and the day after, were first serum-starved for $18 \mathrm{~h}$ and then stimulated with $10 \%$ FBS for 15 min (S) or left unstimulated (NS). Subsequently, immunoprecipitation (IP) with (A) antiRalGPS2, (B) anti-LST1 or (C) anti-Sec5 antibodies were performed, as indicated in each panel. Immunoprecipitates were probed for Sec5, LST1, RalA and RalGPS2 presence. tLST1: LST1 trimerous; mLST1: LST1 monomer.

\section{Discussion}

The tumor microenvironment plays a fundamental role in cancer progression and resistance [63]. Tumors are not merely a mass of cancer cells; they are also a heterogeneous environment where cancer cells recruit stromal, immune system and endothelial cells by secreting growth factors and cytokines. In turn, the recruited cells, such as cancerassociated fibroblasts (CAFs) $[64,65]$, secrete signals and metabolites that support the growth of cancer cells. The communication between these cells in the tumor mass is not due exclusively to paracrine signaling, but it is also based on a network of membranous protrusions, the tunneling nanotubes. Through TNTs, cells can directly exchange small molecules and organelles [66], providing them with new traits, such as chemoresistance, migratory phenotype and metabolic plasticity [67]. Functional TNTs were observed in several types of cancer and were also imaged in intact tumors, proving their potential in vivo relevance $[19,68]$.

Originally reported in 2004 by Rustom et al. in rat Pheochromocytoma (PC12), Human Embryonic Kidney (HEK293) and Normal Rat Kidney (NRK) cells [9], TNTs are highways 
for intracellular organelles and proteins. They act as an inter-cellular transport system. They have subsequently been identified in several eukaryotic cells, including urothelial [33,69], neuronal, immune [15] and primary cells [70].

Similar structures have been found in bacteria. Such structures allow the production of antibiotics, secretion of virulence factors and bioluminescence [71].

RalA overexpression is associated with several different types of human cancers, in particular bladder cancer [72], which represents a major epidemiological problem and whose incidence continues to increase each year.

In our study, we focused our attention on the bladder cancer microenvironment, using a panel of six cell lines representative of bladder cancers at different stages and grades. We demonstrated that TNTs formation correlates with the stage: active TNTs, able to transfer mitochondria, are formed only between cells at mid and high stages. Usually, the transfer of mitochondria through tunneling nanotubes occurs preferentially from endothelial cells to cancer cells, for example, by conferring them chemoresistance [73]. However, several studies report that the exchange also takes place between cells of the same type [18,49].

Mitochondria are the powerhouses of the cell, and their acquisition by a donor cell confers a metabolic potential capable of guaranteeing significant survival benefits under stressful conditions. In fact, under nutritional shortness, mitochondrial respiration enables a high yield of ATP production per unit of moles of consumed glucose. This, in turn, ensures the cell can get energy from the oxidation of other carbon sources, such as amino acids, fatty acids and lactate, which can also support the anaplerosis in hyper-glycolytic cells where glucose follows a fermentative route (aerobic glycolysis, or Warburg effect).

Therefore, the transfer of mitochondria can supply energy and metabolic support to tumor cells, possibly mitochondria-defective cells, allowing aggressive phenotypes typical of different kinds of cancer [52,56]. Mitochondria uptake could also support cell resistance to stress by promoting aerobic respiration, decreasing ROS production and increasing survival [74-77].

To further characterize TNTs in the six bladder cancer cell lines under investigation, we analyzed the expression of proteins involved in TNTs generation: namely, RalA GTPase and RalGPS2 [40,44]. RalA contributes to the control of actin cytoskeletal remodeling and vesicular transport via interaction with the exocyst complex [78]. Previous work suggests that RalA may coordinate with M-Sec and exocyst to initiate TNTs formation and elongation [44]. RalGPS2 is a Ras-independent GEF for RalA, which contains a PH domain and a SH3-binding region, and it is involved in cytokinesis, the control of cell cycle progression, differentiation, organization and rearrangement of cytoskeleton and TNTs development in PC12 and 5637 cells [40,45,61]. Moreover, the RALGPS2 gene is regulated by HIF- $2 \alpha$ and directly affects endothelial sprouting during prolonged hypoxic culturing [79].

The expression of RalGPS2 and RalA is very low in UMUC-3 and J82 high-stage and grade cell lines, while it is very high in 5637 and HT1376 cells. Among the bladder cancer cell lines studied in our work, only UMUC-3 expresses an oncogenic mutant of KRas, namely KRasG12C [48,80-82]. Thus, although UMUC3 cells display the highest percentage of functional TNTs, the presence of KRas mutation does not make them suitable as model cell lines to study the TNTs microenvironment in bladder cancer cells. Indeed, hyperactivated Ras directly affects RalA activity [83,84].

Smith and colleagues, in 2007, demonstrated, in bladder cancer, that the overexpression of RalA is associated with tumors of high-stage and grade. However, RalA protein has a lower expression in UMUC3 and J82 cells compared to RT4 and 5637 cells. These apparently conflicting results can be explained by the fact that despite lower levels of total RalA, high-stage and grade cells contain a higher fraction of the protein in the active state, as demonstrated in J82 cells [85]. Analysis of human bladder cancer cell lines also revealed RalA activation, which cannot be caused by protein mutations affecting its intrinsic GTP-binding activity [86]. 
The presence of multiple isoforms of RalGPS2 protein may be due to alternative splicing or post-translational modification variants $[45,87]$. This aspect had already been reported in different mouse tissues [45]. In conclusion, here we show that there is no correlation between the expression levels of RalA and RalGPS2 and the formation of tunneling nanotubes.

TNTs can transfer proteins. For example, TNTs connecting B and T cells transfer H-Ras protein from B to T cells [51]; in addition, TNTs facilitate the direct intercellular transfer of oncogenic K-Ras between colorectal cancer cells [50]. TNTs observed in 5637 cells are functionally active and involved in mitochondrial trafficking; here, we demonstrated that TNTs in bladder cancer cells are also able to transport molecules important for TNTs development, such as LST1 and RalA, but not RalGPS2. Our work provides, for the first time, evidence that TNTs transfer RalA GTPase from cell to cell.

Taking into account that RalA is necessary for the anchorage-independent growth of cancer cells and its overexpression is associated with several different types of human tumors, our data are of particular interest [85].

Different studies have demonstrated that stressful states (e.g., inflammation, high glucose and low $\mathrm{pH}$ growth medium, low serum, ultraviolet radiation, temperature, $\mathrm{H}_{2} \mathrm{O}_{2}$ ) can boost TNTs generation between cells [18,19,88,89]. Furthermore, previous works have shown that under stress conditions, cells release proteins or metabolites into the culture medium. Such released factors can act as 'call-for-help' signals for other cells, leading to nanotubes formation [90]. In the present work, we show that TNTs are formed spontaneously during in vitro growth: however, they are most abundant in acidified lowserum medium (LSA) or in oxidative stress medium ( $\left.\mathrm{HS}+\mathrm{H}_{2} \mathrm{O}_{2}\right)$ in 5637 and $\mathrm{HEK} 293$ cells, respectively. Notably, LSA mimics the acidified tumor microenvironment deriving from the fermentative activity of hyperglycolytic proliferating cancer cells. This condition is known to support the invasive potential of cancer cells, most likely contributing to TNTs formation $[19,91]$. Conversely, hydrogen peroxide $\left(\mathrm{H}_{2} \mathrm{O}_{2}\right)$, one of the most abundant oxygen reactive species (ROS), has been demonstrated to induce cell injury through lipid oxidation and DNA damage triggering cellular apoptotic pathways [92-97]. In addition to these effects, $\mathrm{H}_{2} \mathrm{O}_{2}$ promotes actin polymerization, co-localization of myosin Va with F-actin and tunneling nanotubes formation among astrocytes [98]. In this scenario, with our work, we demonstrate that the enhancement of TNTs generation caused by stressful media is the consequence of RalGPS2 up-regulation. Indeed, the knock-down of RalGPS2 inhibits TNTs development. Taken together, our findings pinpoint RalGPS2 as a key regulator of nanotubes formation.

Another important regulator of TNTs generation is p53. Wang et al., in 2011, have demonstrated that hydrogen peroxide $\left(\mathrm{H}_{2} \mathrm{O}_{2}\right)$ induces p53 activation (phospho-p53), which in turn boosts TNTs development between primary rat hippocampal astrocytes and neurons [49]. Moreover, other studies demonstrated that p53, as well as CDC42, myosin X (MyoD), M-Sec (also called B94 or tumor necrosis factor-induced protein 2; TNF $\alpha$ IP2), RalA-GTP, LST1 and exocyst complex are important regulators of nanotubes formation $[49,60,99,100]$. In the present study, we showed that even though phospho-p53 (p53 P) interacts with RalGPS2, stressful conditions modulate only RalGPS2 expression, while p53 activation is not affected. However, though phospho-p53 levels do not seem to change until the $24 \mathrm{~h}$ timepoint, it interacts with RalGPS2, as well as with TNF $\alpha \mathrm{IP} 2$. These findings suggest a possible role of phospho-p53 and TNF $\alpha$ IP2 in the RalGPS2 activation complex involved in TNTs generation. In fact, Wang et al. demonstrated that under stressful states, active p53 up-regulate both EGFR and TNF $\alpha$ IP2 [49].

Among the pathways involved in nanotubes development, the Akt/PI3K/mTOR signaling pathway plays a crucial role. In fact, in human malignant pleural mesothelioma cell lines, hyperactivation of this signal cascade by low-serum growth medium promotes TNTs formation [19]. The Akt signaling pathway is involved in the regulation of F-actin polymerization, production of cellular protrusions, cell polarization and adhesion [101-103], which are necessary to form mature and stabilized TNTs [104]. Furthermore, our group has 
previously demonstrated that RalGPS2 regulates Akt activation [40]. Notably, the silencing of RalGPS2 partially inhibits Akt phosphorylation, while its overexpression increases it [40]. In the current work, we show that the ability of RalGPS2 to modulate Akt activation is promoted by the interaction between RalGPS2, Akt (total and active Akt) and PDK1 kinase. PDK1 is the protein kinase responsible for Akt phosphorylation and activation in the plasma membranes [105]. These findings, together with those obtained by D'Aloia et al., in 2018 [40], suggest that RalGPS2 may contribute to Akt activation, acting as a scaffold protein and enabling PDK1 to come within close proximity with Akt. Similar results have already been observed for the Ras-dependent Ral GEFs family, RalGDS. Indeed, RalGDS promotes Akt phosphorylation via PDK1 by bringing these two kinases together [106].

RalGPS2, as described by Ceriani et al., is a RalA GEF containing a Cdc25-like GEF domain and a pleckstrin homology $(\mathrm{PH})$ domain in the $\mathrm{C}$ terminus. The latter binds phosphatidylinositol-4,5-bisphosphate $\left(\mathrm{PIP}_{2}\right)$ but, at a lower extent, also binds phosphatidylinositol 3-4-5-triphosphate ( $\left.\mathrm{PIP}_{3}\right)$, both are PI3K products [45]. Moreover, phosphatidylinositol 3-kinase (PI3K) is the protein kinase that, together with PDK1, contributes to Akt activation. The most well-established model of Akt phosphorylation involves ligandinduced activation of PI3K, which in turn leads to the production of the phospholipids PIP $_{2}$ and $\mathrm{PIP}_{3}$ [107]. These phospholipids interact with the PH domains of Akt and PDK1 in the plasma membrane, where PDK1 phosphorylates Akt on threonine 308 [105]. In this work, we demonstrate that the use of wortmannin, a potent, selective and irreversible PI3K inhibitor, disrupts TNTs development both in 5637 and HEK293 cell lines, although these cells had been treated with TNTs-inducer media (stress media). Our findings prove the prominent role of PI3K in TNTs formation. Our hypothesis is that the inhibition of PI3K by wortmannin impairs RalGPS2 localization in plasma membranes. Indeed, despite the fact that stress conditions can increase RalGPS2 expression, the blockage of PI3K activity inhibits the production of $\mathrm{PIP}_{2}$ and $\mathrm{PIP}_{3}$, and consequently, the anchorage of RalGPS2 at the plasma membrane. Moreover, we demonstrated that Akt activation is essential for TNTs formation in 5637 cells, as the use of a selective Akt inhibitor (A6730) impairs TNTs generation. Conversely, the Akt pathway does not play an important role in nanotubes development in HEK293 cells. This is in agreement with the notion that different mechanisms are present, which promote TNTs formation in several types of cells.

D'Aloia et al. demonstrated that RalGPS2 interacts with LST1 and RalA, leading to the formation of a complex that promotes TNTs generation in 5637 cells [40]. In the current work, we have shown that this complex is also formed in HEK293 cell lines, and it is likely to be responsible for TNTs development in these cells.

Taken together, our results extend the molecular machinery shown by D'Aloia et al. [40]. In this study, stress conditions boost RalGPS2 expression and induce PI3K activation, which in turn leads to the production of $\mathrm{PIP}_{2}$ and $\mathrm{PIP}_{3}$. These phospholipids are substrates of the PH domain of Akt, PDK1 and RalGPS2 in the plasma membrane, where RalGPS2 may contribute to Akt activation, acting as a scaffold protein for PDK1 and Akt. In this context, PDK1 phosphorylates Akt and in turn activates the Akt signal cascade, which controls TNTs formation through mTOR pathways, or cell proliferation, through p21 and p27 inhibition. Moreover, in this scenario, RalGPS2, recruited to the plasma membrane by PI3K products, also interacts with phospho-p53, TNF $\alpha$ IP2, LST1 and RalA, leading to the assembly of a specific multimolecular complex. Under a stressful state, this complex allows RalA-Sec5 interaction and activation (assembly of exocyst complex), which prompts TNTs development (graphical abstract).

\section{Conclusions}

The exchange of material through TNT connections gives cancer cells, in the context of the tumoral microenvironment, specific traits (e.g., enhanced metabolic plasticity, migratory phenotypes, angiogenic ability and therapy resistance). In this paper, we demonstrate that TNTs formed by bladder cancer cells of mid and high-stages with invasive properties [108] are functionally active and transport organelles, such as mitochondria, and 
proteins involved in bladder cancer malignancy and in nanotubes formation, such as RalA GTPase and LST1. Furthermore, we characterized the molecular machinery underlying TNTs formation in bladder cancer and kidney cells and unveiled the crucial role played by RalGPS2, which promotes tunneling nanotubes formation through interaction with Akt and PDK1.

We also demonstrate that TNTs formation is induced upon a specific stress condition. The diversity in specific stress stimuli considered may reflectthe different roles played by some molecules involved in TNTs development. For instance, in HEK293 cells, TNTs are formed in response to oxidative insults: RalGPS2 is essential in the process, while Akt is dispensable. Conversely, in 5637 cells, TNTs are formed in response to medium acidification and serum limitation: in this model, RalGPS2, as well as Akt, are crucial for TNTs formation. Given the crucial role of TNTs in tumor progression, TNTs-interfering drugs represent a new frontier to reduce cellular invasiveness and pave a new way towards clinical application. Clearly, this gives an idea of how the development of precision medicine is essential in the treatment of certain types of diseases, such as cancer, where patients must be stratified based on markers to be subjected to more effective and less toxic targeted therapies. In this study, RalGPS2 emerges as a potential common pharmacological target for the development of TNTs-interfering drugs that can reduce tumor progression, at least in bladder cancer, by blocking supportive intercellular mechanisms within the tumor microenvironment.

Supplementary Materials: The following are available online at https:/ /www.mdpi.com/article/10 .3390/cancers13246330/s1, https:/ zenodo.org/record/5603158\#.YXIF4VVBzcs (accessed on 13 December 2021). Figure S1: Mitochondria transfer via TNTs in bladder cancer cell lines, Figure S2: TNTs transfer mitochondria independently by their membrane potential in bladder cancer cell lines, Figure S3: Acidified hyperglycemic low-serum medium induces TNTs formation in 5637 cells, Figure S4: Oxidative stress induces TNTs formation in HEK293 cells, Figure S5: Original western blots for Figure 5, Figure S6: Original western blots for Figure 9, Figure S7: Original western blots for Figure 10, Figure S8: Original western blots for Figure 12, Video S1: Intracellular transport via TNTs of mobile RalA in 5637 cells, Video S2: RalGPS2 is not transported via TNTs in 5637 cells, Video S3: Intracellular transport via TNTs of mobile LST1 in 5637 cells.

Author Contributions: A.D. and M.C. conceived the study and designed the experiments; A.D. performed all experiments and prepared figures; E.A. performed Operetta experiments; A.D., M.C., E.S. and E.A. wrote the manuscript; B.C. and A.D. performed statistical analyses; M.C., E.S., A.D. and E.A. created the resources; E.S., B.C., G.B. and E.M. read, corrected and provided feed-back. All authors have read and agreed to the published version of the manuscript.

Funding: This work was supported by funds from the Italian Ministry of University and Research (MIUR) through the grants "Research facilitation fund (Fondo per le Agevolazioni alla Ricerca-FAR)" to MC, ES, BC and EM, and "Dipartimenti di Eccellenza 2017" to the University of Milano Bicocca.

Institutional Review Board Statement: Not applicable.

Informed Consent Statement: Not applicable.

Data Availability Statement: The data presented in the current study are available from the first and corresponding author (M.C.) upon reasonable request.

Acknowledgments: The authors gratefully acknowledge the Milan Center for Neuroscience (NeuroMi), SYSBIO/ISBE.IT Center of Systems Biology and the Project of Excellence CHRONOS (Chronicle multifactorial disorders explored by novel integrated Strategies) for providing the advanced technologies used in this study. The author acknowledges Alessandra Fornarelli for her contribution to the English revision process.

Conflicts of Interest: The authors declare no conflict of interest. 


\section{References}

1. Sung, H.; Ferlay, J.; Siegel, R.L.; Laversanne, M.; Soerjomataram, I.; Jemal, A.; Bray, F. Global Cancer Statistics 2020: GLOBOCAN Estimates of Incidence and Mortality Worldwide for 36 Cancers in 185 Countries. CA Cancer J. Clin. 2021, 71, 209-249. [CrossRef] [PubMed]

2. Jalanko, T.; de Jong, J.J.; Gibb, E.A.; Seiler, R.; Black, P.C. Genomic Subtyping in Bladder Cancer. Curr. Urol. Rep. 2020, 21, 1-10. [CrossRef] [PubMed]

3. Van Den Bosch, S.; Witjes, J.A. Long-Term Cancer-Specific Survival in Patients with High-Risk, Non-Muscle-Invasive Bladder Cancer and Tumour Progression: A Systematic Review. Eur. Urol. 2011, 60, 493-500. [CrossRef] [PubMed]

4. Alfred Witjes, J.; Lebret, T.; Compérat, E.M.; Cowan, N.C.; De Santis, M.; Bruins, H.M.; Hernández, V.; Espinós, E.L.; Dunn, J.; Rouanne, M.; et al. Updated 2016 EAU Guidelines on Muscle-Invasive and Metastatic Bladder Cancer. Eur. Urol. 2017, 71, 462-475. [CrossRef]

5. Yang, Y.; Liu, C.; Yang, X. Endoscopic Molecular Imaging plus Photoimmunotherapy: A New Strategy for Monitoring and Treatment of Bladder Cancer. Mol. Ther.-Oncolytics 2020, 18, 409-418. [CrossRef] [PubMed]

6. Dieleman, J.; Campbell, M.; Chapin, A.; Eldrenkamp, E.; Fan, V.Y.; Haakenstad, A.; Kates, J.; Liu, Y.; Matyasz, T.; Micah, A.; et al. Evolution and Patterns of Global Health Financing 1995-2014: Development Assistance for Health, and Government, Prepaid Private, and out-of-Pocket Health Spending in 184 Countries. Lancet 2017, 389, 1981-2004. [CrossRef]

7. Lee, L.J.; Kwon, C.S.; Forsythe, A.; Mamolo, C.M.; Masters, E.T.; Jacobs, I.A. Humanistic and Economic Burden of Non-Muscle Invasive Bladder Cancer: Results of Two Systematic Literature Reviews. Clin. Outcomes Res. 2020, 12, 693-709. [CrossRef]

8. Nishida-Aoki, N.; Gujral, T.S. Review Emerging Approaches to Study Cell-Cell Interactions in Tumor Microenvironment. Oncotarget 2019, 10, 785-797. [CrossRef] [PubMed]

9. Rustom, A.; Saffrich, R.; Markovic, I.; Walther, P.; Gerdes, H.H. Nanotubular Highways for Intercellular Organelle Transport. Science 2004, 303, 1007-1010. [CrossRef]

10. Roehlecke, C.; Schmidt, M.H.H. Tunneling Nanotubes and Tumor Microtubes in Cancer. Cancers 2020, 12, 857. [CrossRef]

11. Ahmad, T.; Mukherjee, S.; Pattnaik, B.; Kumar, M.; Singh, S.; Rehman, R.; Tiwari, B.K.; Jha, K.A.; Barhanpurkar, A.P.; Wani, M.R.; et al. Miro1 Regulates Intercellular Mitochondrial Transport \& Enhances Mesenchymal Stem Cell Rescue Efficacy. EMBO J. 2014, 33, 994-1010. [CrossRef]

12. Abounit, S.; Bousset, L.; Loria, F.; Zhu, S.; Chaumont, F.; Pieri, L.; Olivo-Marin, J.; Melki, R.; Zurzolo, C. Tunneling Nanotubes Spread Fibrillar A-synuclein by Intercellular Trafficking of Lysosomes. EMBO J. 2016, 35, 2120-2138. [CrossRef]

13. Bhat, S.; Ljubojevic, N.; Zhu, S.; Fukuda, M.; Echard, A.; Zurzolo, C. Rab35 and Its Effectors Promote Formation of Tunneling Nanotubes in Neuronal Cells. Sci. Rep. 2020, 10, 1-14. [CrossRef]

14. Schiller, C.; Huber, J.E.; Diakopoulos, K.N.; Weiss, E.H. Tunneling Nanotubes Enable Intercellular Transfer of MHC Class I Molecules. Hum. Immunol. 2013, 74, 412-416. [CrossRef]

15. Sowinski, S.; Jolly, C.; Berninghausen, O.; Purbhoo, M.A.; Chauveau, A.; Köhler, K.; Oddos, S.; Eissmann, P.; Brodsky, F.M.; Hopkins, C.; et al. Membrane Nanotubes Physically Connect T Cells over Long Distances Presenting a Novel Route for HIV-1 Transmission. Nat. Cell Biol. 2008, 10, 211-219. [CrossRef]

16. Ariazi, J.; Benowitz, A.; De Biasi, V.; Den Boer, M.L.; Cherqui, S.; Cui, H.; Douillet, N.; Eugenin, E.A.; Favre, D.; Goodman, S.; et al. Tunneling Nanotubes and Gap Junctions-Their Role in Long-Range Intercellular Communication during Development, Health, and Disease Conditions. Front. Mol. Neurosci. 2017, 10, 333. [CrossRef] [PubMed]

17. Lu, J.J.; Yang, W.M.; Li, F.; Zhu, W.; Chen, Z. Tunneling Nanotubes Mediated MicroRNA-155 Intercellular Transportation Promotes Bladder Cancer Cells' Invasive and Proliferative Capacity. Int. J. Nanomed. 2019, 14, 9731-9743. [CrossRef]

18. Wang, X.; Gerdes, H.H. Transfer of Mitochondria via Tunneling Nanotubes Rescues Apoptotic PC12 Cells. Cell Death Differ. 2015, 22, 1181-1191. [CrossRef] [PubMed]

19. Lou, E.; Fujisawa, S.; Morozov, A.; Barlas, A.; Romin, Y.; Dogan, Y.; Gholami, S.; Moreira, A.L.; Manova-Todorova, K.; Moore, M.A.S. Tunneling Nanotubes Provide a Unique Conduit for Intercellular Transfer of Cellular Contents in Human Malignant Pleural Mesothelioma. PLoS ONE 2012, 7, e33093. [CrossRef]

20. Gousset, K.; Schiff, E.; Langevin, C.; Marijanovic, Z.; Caputo, A.; Browman, D.T.; Chenouard, N.; de Chaumont, F.; Martino, A.; Enninga, J.; et al. Prions Hijack Tunnelling Nanotubes for Intercellular Spread. Nat. Cell Biol. 2009, 11, 328-336. [CrossRef] [PubMed]

21. Yasuda, K.; Khandare, A.; Burianovskyy, L.; Maruyama, S.; Zhang, F.; Nasjletti, A.; Goligorsky, M.S. Tunneling Nanotubes Mediate Rescue of Prematurely Senescent Endothelial Cells by Endothelial Progenitors: Exchange of Lysosomal Pool. Aging 2011, 3, 597-608. [CrossRef]

22. Plotnikov, E.Y.; Khryapenkova, T.G.; Galkina, S.I.; Sukhikh, G.T.; Zorov, D.B. Cytoplasm and Organelle Transfer between Mesenchymal Multipotent Stromal Cells and Renal Tubular Cells in Co-Culture. Exp. Cell Res. 2010, 316, 2447-2455. [CrossRef]

23. Ranzinger, J.; Rustom, A.; Abel, M.; Leyh, J.; Kihm, L.; Witkowski, M.; Scheurich, P.; Zeier, M.; Schwenger, V. Nanotube Action between Human Mesothelial Cells Reveals Novel Aspects of Inflammatory Responses. PLoS ONE 2011, 6, e29537. [CrossRef]

24. Salter, R.D.; Watkins, S.C. Dynamic Properties of Antigen Between Dendritic Cells. Immunol. Res. 2006, 36, 211-220. [CrossRef]

25. Xu, W.; Santini, P.A.; Sullivan, J.S.; He, B.; Shan, M.; Ball, S.C.; Dyer, W.B.; Ketas, T.J.; Chadburn, A.; Cohen-Gould, L.; et al. HIV-1 Evades Virus-Specific IgG2 and IgA Responses by Targeting Systemic and Intestinal B Cells via Long-Range Intercellular Conduits. Nat. Immunol. 2009, 10, 1008-1017. [CrossRef] 
26. Gurke, S.; Barroso, J.F.V.; Hodneland, E.; Bukoreshtliev, N.V.; Schlicker, O.; Gerdes, H.H. Tunneling Nanotube (TNT)-like Structures Facilitate a Constitutive, Actomyosin-Dependent Exchange of Endocytic Organelles between Normal Rat Kidney Cells. Exp. Cell Res. 2008, 314, 3669-3683. [CrossRef]

27. Thayanithy, V.; Dickson, E.L.; Steer, C.; Subramanian, S.; Lou, E. Tumor-Stromal Cross Talk: Direct Cell-to-Cell Transfer of Oncogenic MicroRNAs via Tunneling Nanotubes. Transl. Res. 2014, 164, 359-365. [CrossRef]

28. Thayanithy, V.; Babatunde, V.; Dickson, E.L.; Wong, P.; Oh, S.; Ke, X.; Barlas, A.; Fujisawa, S.; Romin, Y.; Moreira, A.L.; et al. Tumor Exosomes Induce Tunneling Nanotubes in Lipid Raft-Enriched Regions of Human Mesothelioma Cells. Exp. Cell Res. 2014, 323, 178-188. [CrossRef] [PubMed]

29. Desir, S.; O’Hare, P.; Vogel, R.I.; Sperduto, W.; Sarkari, A.; Dickson, E.L.; Wong, P.; Nelson, A.C.; Fong, Y.; Steer, C.J.; et al. Chemotherapy-Induced Tunneling Nanotubes Mediate Intercellular Drug Efflux in Pancreatic Cancer. Sci. Rep. 2018, 8, 1-13. [CrossRef]

30. Vidulescu, C.; Clejan, S.; O'Connor, K.C. Vesicle Traffic through Intercellular Bridges in DU 145 Human Prostate Cancer Cells. J. Cell. Mol. Med. 2004, 8, 388-396. [CrossRef] [PubMed]

31. Önfelt, B.; Nedvetzki, S.; Benninger, R.K.P.; Purbhoo, M.A.; Sowinski, S.; Hume, A.N.; Seabra, M.C.; Neil, M.A.A.; French, P.M.W.; Davis, D.M. Structurally Distinct Membrane Nanotubes between Human Macrophages Support Long-Distance Vesicular Traffic or Surfing of Bacteria. J. Immunol. 2006, 177, 8476-8483. [CrossRef]

32. Gerdes, H.H.; Carvalho, R.N. Intercellular Transfer Mediated by Tunneling Nanotubes. Curr. Opin. Cell Biol. 2008, $20,470-475$. [CrossRef] [PubMed]

33. Veranič, P.; Lokar, M.; Schütz, G.J.; Weghuber, J.; Wieser, S.; Hägerstrand, H.; Kralj-Iglič, V.; Iglič, A. Different Types of Cell-to-Cell Connections Mediated by Nanotubular Structures. Biophys. J. 2008, 95, 4416-4425. [CrossRef] [PubMed]

34. Wang, X.; Veruki, M.L.; Bukoreshtliev, N.V.; Hartveit, E.; Gerdes, H.H. Animal Cells Connected by Nanotubes Can Be Electrically Coupled through Interposed Gap-Junction Channels. Proc. Natl. Acad. Sci. USA 2010, 107, 17194-17199. [CrossRef]

35. Gousset, K.; Marzo, L.; Commere, P.H.; Zurzolo, C. Myo10 Is a Key Regulator of TNT Formation in Neuronal Cells. J. Cell Sci. 2013, 126, 4424-4435. [CrossRef]

36. Schiller, C.; Diakopoulos, K.N.; Rohwedder, I.; Kremmer, E.; von Toerne, C.; Ueffing, M.; Weidle, U.H.; Ohno, H.; Weiss, E.H. LST1 Promotes the Assembly of a Molecular Machinery Responsible for Tunneling Nanotube Formation. J. Cell Sci. 2013, 126, 767-777. [CrossRef] [PubMed]

37. Ohno, H.; Hase, K.; Kimura, S. M-Sec: Emerging Secrets of Tunneling Nanotube Formation. Commun. Integr. Biol. 2010, 3, $231-233$. [CrossRef] [PubMed]

38. Mittal, R.; Karhu, E.; Wang, J.S.; Delgado, S.; Zukerman, R.; Mittal, J.; Jhaveri, V.M. Cell Communication by Tunneling Nanotubes: Implications in Disease and Therapeutic Applications. J. Cell. Physiol. 2019, 234, 1130-1146. [CrossRef]

39. Andresen, V.; Wang, X.; Ghimire, S.; Omsland, M.; Gjertsen, B.T.; Gerdes, H.H. Tunneling Nanotube (TNT) Formation Is Independent of P53 Expression. Cell Death Differ. 2013, 20, 1124. [CrossRef]

40. D'Aloia, A.; Berruti, G.; Costa, B.; Schiller, C.; Ambrosini, R.; Pastori, V.; Martegani, E.; Ceriani, M. RalGPS2 Is Involved in Tunneling Nanotubes Formation in 5637 Bladder Cancer Cells. Exp. Cell Res. 2018, 362, 349-361. [CrossRef]

41. Albright, C.F.; Giddings, B.W.; Liu, J.; Vito, M.; Weinberg, R.A. Characterization of a Guanine Nucleotide Dissociation Stimulator for a Ras-Related GTPase. EMBO J. 1993, 12, 339-347. [CrossRef]

42. Hernandez-Muñoz, I.; Malumbres, M.; Leonardi, P.; Pellicer, A. The Rgr Oncogene (Homologous to RalGDS) Induces Transformation and Gene Expression by Activating Ras, Ral and Rho Mediated Pathways. Oncogene 2000, 19, 2745-2757. [CrossRef]

43. Wolthuis, R.M.F.; De Ruiter, N.D.; Cool, R.H.; Bos, J.L. Stimulation of Gene Induction and Cell Growth by the Ras Effector Rlf. EMBO J. 1997, 16, 6748-6761. [CrossRef]

44. Hase, K.; Kimura, S.; Takatsu, H.; Ohmae, M.; Kawano, S.; Kitamura, H.; Ito, M.; Watarai, H.; Hazelett, C.C.; Yeaman, C.; et al. M-Sec Promotes Membrane Nanotube Formation by Interacting with Ral and the Exocyst Complex. Nat. Cell Biol. 2009, 11, 1427-1432. [CrossRef] [PubMed]

45. Ceriani, M.; Scandiuzzi, C.; Amigoni, L.; Tisi, R.; Berruti, G.; Martegani, E. Functional Analysis of RalGPS2, a Murine Guanine Nucleotide Exchange Factor for RalA GTPase. Exp. Cell Res. 2007, 313, 2293-2307. [CrossRef] [PubMed]

46. Neyraud, V.; Aushev, V.N.; Hatzoglou, A.; Meunier, B.; Cascone, I.; Camonis, J. RalA and RalB Proteins Are Ubiquitinated GTPases, and Ubiquitinated RalA Increases Lipid Raft Exposure at the Plasma Membrane. J. Biol. Chem. 2012, 287, 29397-29405. [CrossRef]

47. Schiller, C.; Nitschké, M.J.E.; Seidl, A.; Kremmer, E.; Weiss, E.H. Rat Monoclonal Antibodies Specific for LST1 Proteins. Hybridoma 2009, 28, 281-286. [CrossRef] [PubMed]

48. Zuiverloon, T.C.M.; De Jong, F.C.; Costello, J.C.; Theodorescu, D. Systematic Review: Characteristics and Preclinical Uses of Bladder Cancer Cell Lines. Bladder Cancer 2018, 4, 169-183. [CrossRef]

49. Wang, Y.; Cui, J.; Sun, X.; Zhang, Y. Tunneling-Nanotube Development in Astrocytes Depends on P53 Activation. Cell Death Differ. 2011, 18, 732-742. [CrossRef]

50. Desir, S.; Wong, P.; Turbyville, T.; Chen, D.; Shetty, M.; Clark, C.; Zhai, E.; Romin, Y.; Manova-Todorova, K.; Starr, T.K.; et al. Intercellular Transfer of Oncogenic KRAS via Tunneling Nanotubes Introduces Intracellular Mutational Heterogeneity in Colon Cancer Cells. Cancers 2019, 11, 892. [CrossRef] 
51. Rainy, N.; Chetrit, D.; Rouger, V.; Vernitsky, H.; Rechavi, O.; Marguet, D.; Goldstein, I.; Ehrlich, M.; Kloog, Y. H-Ras Transfers from B to T Cells via Tunneling Nanotubes. Cell Death Dis. 2013, 4, e726. [CrossRef] [PubMed]

52. Hekmatshoar, Y.; Nakhle, J.; Galloni, M.; Vignais, M.L. The Role of Metabolism and Tunneling Nanotube-Mediated Intercellular Mitochondria Exchange in Cancer Drug Resistance. Biochem. J. 2018, 475, 2305-2328. [CrossRef]

53. Parker, I.; Evans, K.T.; Ellefsen, K.; Lawson, D.A.; Smith, I.F. Lattice Light Sheet Imaging of Membrane Nanotubes between Human Breast Cancer Cells in Culture and in Brain Metastases. Sci. Rep. 2017, 7, 1-7. [CrossRef]

54. Bénard, M.; Schapman, D.; Lebon, A.; Monterroso, B.; Bellenger, M.; Le Foll, F.; Pasquier, J.; Vaudry, H.; Vaudry, D.; Galas, L. Structural and Functional Analysis of Tunneling Nanotubes (TnTs) Using GCW STED and Gconfocal Approaches. Biol. Cell 2015, 107, 419-425. [CrossRef] [PubMed]

55. Pinto, G.; Saenz-De-Santa-Maria, I.; Chastagner, P.; Perthame, E.; Delmas, C.; Toulas, C.; Moyal-Jonathan-Cohen, E.; Brou, C.; Zurzolo, C. Patient-Derived Glioblastoma Stem Cells Transfer Mitochondria through Tunneling Nanotubes in Tumor Organoids. Biochem. J. 2021, 478, 21-39. [CrossRef] [PubMed]

56. Vignais, M.L.; Caicedo, A.; Brondello, J.M.; Jorgensen, C. Cell Connections by Tunneling Nanotubes: Effects of Mitochondrial Trafficking on Target Cell Metabolism, Homeostasis, and Response to Therapy. Stem. Cells Int. 2017, 2017. [CrossRef]

57. Torab, P.; Yan, Y.; Yamashita, H.; Warrick, J.I.; Raman, J.D.; Degraff, D.J.; Wong, P.K. Three-Dimensional Microtumors for Probing Heterogeneity of Invasive Bladder Cancer. Anal. Chem. 2020, 92, 8768-8775. [CrossRef] [PubMed]

58. Joneson, T.; White, M.A.; Wigler, M.H.; Bar-Sagi, D. Stimulation of Membrane Ruffling and MAP Kinase Activation by Distinct Effectors of RAS. Science 1996, 271, 810-812. [CrossRef] [PubMed]

59. Desir, S.; Dickson, E.L.; Vogel, R.I.; Thayanithy, V.; Wong, P.; Teoh, D.; Geller, M.A.; Steer, C.J.; Subramanian, S.; Lou, E. Tunneling Nanotube Formation Is Stimulated by Hypoxia in Ovarian Cancer Cells. Oncotarget 2016, 7, 43150-43161. [CrossRef]

60. Sisakhtnezhad, S.; Khosravi, L. Emerging Physiological and Pathological Implications of Tunneling Nanotubes Formation between Cells. Eur. J. Cell Biol. 2015, 94, 429-443. [CrossRef]

61. Ceriani, M.; Amigoni, L.; Scandiuzzi, C.; Berruti, G.; Martegani, E. The PH-PxxP Domain of RalGPS2 Promotes PC12 Cells Differentiation Acting as a Dominant Negative for RalA GTPase Activation. Neurosci. Res. 2010, 66, 290-298. [CrossRef]

62. Nguyen, D.; Liao, W.; Zeng, S.X.; Lu, H. Reviving the Guardian of the Genome: Small Molecule Activators of P53. Pharmacol. Ther. 2017, 178, 92-108. [CrossRef]

63. Yuan, Y.; Jiang, Y.C.; Sun, C.K.; Chen, Q.M. Role of the Tumor Microenvironment in Tumor Progression and the Clinical Applications (Review). Oncol. Rep. 2016, 35, 2499-2515. [CrossRef]

64. Cirri, P.; Chiarugi, P. Cancer Associated Fibroblasts: The Dark Side of the Coin. Am. J. Cancer Res. 2011, 1, 482-497. [PubMed]

65. Cirri, P.; Chiarugi, P. Cancer-Associated-Fibroblasts and Tumour Cells: A Diabolic Liaison Driving Cancer Progression. Cancer Metastasis Rev. 2012, 31, 195-208. [CrossRef]

66. Lou, E. A Ticket to Ride: The Implications of Direct Intercellular Communication via Tunneling Nanotubes in Peritoneal and Other Invasive Malignancies. Front. Oncol. 2020, 10, 2478. [CrossRef] [PubMed]

67. Pinto, G.; Brou, C.; Zurzolo, C. Tunneling Nanotubes: The Fuel of Tumor Progression? Trends Cancer 2020, 6, 874-888. [CrossRef] [PubMed]

68. Osswald, M.; Jung, E.; Sahm, F.; Solecki, G.; Venkataramani, V.; Blaes, J.; Weil, S.; Horstmann, H.; Wiestler, B.; Syed, M.; et al. Brain Tumour Cells Interconnect to a Functional and Resistant Network. Nature 2015, 528, 93-98. [CrossRef]

69. Kabaso, D.; Lokar, M.; Kralj-Iglič, V.; Veranič, P.; Iglič, A. Temperature and Cholera Toxin B Are Factors That Influence Formation of Membrane Nanotubes in RT4 and T24 Urothelial Cancer Cell Lines. Int. J. Nanomed. 2011, 6, 495-509. [CrossRef]

70. Gerdes, H.H.; Rustom, A.; Wang, X. Tunneling Nanotubes, an Emerging Intercellular Communication Route in Development. Mech. Dev. 2013, 130, 381-387. [CrossRef]

71. Ng, W.L.; Bassler, B.L. Bacterial Quorum-Sensing Network Architectures. Annu. Rev. Genet. 2009, 43, 197-222. [CrossRef] [PubMed]

72. Saito, R.; Shirakawa, R.; Nishiyama, H.; Kobayashi, T.; Kawato, M.; Kanno, T.; Nishizawa, K.; Matsui, Y.; Ohbayashi, T.; Horiguchi, M.; et al. Downregulation of Ral GTPase-Activating Protein Promotes Tumor Invasion and Metastasis of Bladder Cancer. Oncogene 2013, 32, 894-902. [CrossRef]

73. Pasquier, J.; Guerrouahen, B.S.; Al Thawadi, H.; Ghiabi, P.; Maleki, M.; Abu-Kaoud, N.; Jacob, A.; Mirshahi, M.; Galas, L.; Rafii, S.; et al. Preferential Transfer of Mitochondria from Endothelial to Cancer Cells through Tunneling Nanotubes Modulates Chemoresistance. J. Transl. Med. 2013, 11, 94. [CrossRef]

74. Oliva, C.R.; Moellering, D.R.; Gillespie, G.Y.; Griguer, C.E. Acquisition of Chemoresistance in Gliomas Is Associated with Increased Mitochondrial Coupling and Decreased ROS Production. PLoS ONE 2011, 6, 9-13. [CrossRef]

75. Omsland, M.; Bruserud, Ø.; Gjertsen, B.T.; Andresen, V. Tunneling Nanotube (TNT) Formation Is Downregulated by Cytarabine and NF-KB Inhibition in Acute Myeloid Leukemia (AML). Oncotarget 2017, 8, 7946-7963. [CrossRef]

76. Spees, J.L.; Olson, S.D.; Whitney, M.J.; Prockop, D.J. Mitochondrial Transfer between Cells Can Rescue Aerobic Respiration. Proc. Natl. Acad. Sci. USA 2006, 103, 1283-1288. [CrossRef]

77. Denise, C.; Paoli, P.; Calvani, M.; Taddei, M.L.; Giannoni, E.; Kopetz, S.; Kazmi, S.M.A.; Pia, M.M.; Pettazzoni, P.; Sacco, E.; et al. 5-Fluorouracil Resistant Colon Cancer Cells Are Addicted to OXPHOS to Survive and Enhance Stem-like Traits. Oncotarget 2015, 6, 41706-41721. [CrossRef] 
78. Moskalenko, S.; Henry, D.O.; Rosse, C.; Mirey, G.; Camonis, J.H.; White, M.A. The Exocyst Is a Ral Effector Complex. Nat. Cell Biol. 2002, 4, 66-72. [CrossRef]

79. Nauta, T.D.; van den Broek, M.; Gibbs, S.; van der Pouw-Kraan, T.C.T.M.; Oudejans, C.B.; van Hinsbergh, V.W.M.; Koolwijk, P. Identification of HIF- $2 \alpha$-Regulated Genes That Play a Role in Human Microvascular Endothelial Sprouting during Prolonged Hypoxia in Vitro. Angiogenesis 2017, 20, 39-54. [CrossRef] [PubMed]

80. Santha, S.; Ling, X.; Aljahdali, I.A.M.; Rasam, S.S.; Wang, X.; Liao, J.; Wang, J.; Fountzilas, C.; Li, Q.; Qu, J.; et al. Mutant Kras as a Biomarker Plays a Favorable Role in FL118-Induced Apoptosis, Reactive Oxygen Species (ROS) Production and Modulation of Survivin, Mcl-1 and XIAP in Human Bladder Cancer. Cancers 2020, 12, 3413. [CrossRef] [PubMed]

81. Li, C.; Teng, R.H.; Tsai, Y.C.; Ke, H.S.; Huang, J.Y.; Chen, C.C.; Kao, Y.L.; Kuo, C.C.; Bell, W.R.; Shieh, B. H-Ras Oncogene Counteracts the Growth-Inhibitory Effect of Genistein in T24 Bladder Carcinoma Cells. Br. J. Cancer 2005, 92, 80-88. [CrossRef]

82. Chen, G.; Oh, S.; Monia, B.P.; Stacey, D.W. Antisense Oligonucleotides Demonstrate a Dominant Role of C-Ki-RAS Proteins in Regulating the Proliferation of Diploid Human Fibroblasts. J. Biol. Chem. 1996, 271, 28259-28265. [CrossRef]

83. Lim, K.H.; Baines, A.T.; Fiordalisi, J.J.; Shipitsin, M.; Feig, L.A.; Cox, A.D.; Der, C.J.; Counter, C.M. Activation of RalA Is Critical for Ras-Induced Tumorigenesis of Human Cells. Cancer Cell 2005, 7, 533-545. [CrossRef] [PubMed]

84. Oxford, G.; Owens, C.R.; Titus, B.J.; Foreman, T.L.; Herlevsen, M.C.; Smith, S.C.; Theodorescu, D. RalA and RalB: Antagonistic Relatives in Cancer Cell Migration. Cancer Res. 2005, 65, 7111-7120. [CrossRef] [PubMed]

85. Smith, S.C.; Oxford, G.; Baras, A.S.; Owens, C.; Havaleshko, D.; Brautigan, D.L.; Safo, M.K.; Theodorescu, D. Expression of Ral GTPases, Their Effectors, and Activators in Human Bladder Cancer. Clin. Cancer Res. 2007, 13, 3803-3813. [CrossRef]

86. Smith, S.C.; Theodorescu, D. The Ral GTPase Pathway in Metastatic Bladder Cancer: Key Mediator and Therapeutic Target. Urol. Oncol. Semin. Orig. Investig. 2009, 27, 42-47. [CrossRef]

87. Martegani, E.; Ceriani, M.; Tisi, R.; Berruti, G. Cloning and Characterization of a New Ral-GEF Expressed in Mouse Testis. Ann. N. Y. Acad. Sci. 2002, 973, 135-137. [CrossRef] [PubMed]

88. Chinnery, H.R.; Pearlman, E.; McMenamin, P.G. Cutting Edge: Membrane Nanotubes In Vivo: A Feature of MHC Class II + Cells in the Mouse Cornea. J. Immunol. 2008, 180, 5779-5783. [CrossRef]

89. Arkwright, P.D.; Luchetti, F.; Tour, J.; Roberts, C.; Ayub, R.; Morales, A.P.; Rodríguez, J.J.; Gilmore, A.; Canonico, B.; Papa, S.; et al. Fas Stimulation of T Lymphocytes Promotes Rapid Intercellular Exchange of Death Signals via Membrane Nanotubes. Cell Res. 2010, 20, 72-88. [CrossRef] [PubMed]

90. Islam, M.N.; Das, S.R.; Emin, M.T.; Wei, M.; Sun, L.; Westphalen, K.; Rowlands, D.J.; Quadri, S.K.; Bhattacharya, S.; Bhattacharya, J. Mitochondrial Transfer from Bone-Marrow-Derived Stromal Cells to Pulmonary Alveoli Protects against Acute Lung Injury. Nat. Med. 2012, 18, 759-765. [CrossRef]

91. Martínez-Zaguilán, R.; Seftor, E.A.; Seftor, R.E.B.; Chu, Y.W.; Gillies, R.J.; Hendrix, M.J.C. Acidic PH Enhances the Invasive Behavior of Human Melanoma Cells. Clin. Exp. Metastasis 1996, 14, 176-186. [CrossRef]

92. Butterfield, D.A.; Lauderback, C.M. Lipid Peroxidation and Protein Oxidation in Alzheimer's Disease Brain: Potential Causes and Consequences Involving Amyloid $\beta$-Peptide-Associated Free Radical Oxidative Stress. Free Radic. Biol. Med. 2002, 32, 1050-1060. [CrossRef]

93. Howe, C.J.; LaHair, M.M.; McCubrey, J.A.; Franklin, R.A. Redox Regulation of the Calcium/Calmodulin-Dependent Protein Kinases. J. Biol. Chem. 2004, 279, 44573-44581. [CrossRef]

94. Huang, X.; Moir, R.D.; Tanzi, R.E.; Bush, A.I.; Rogers, J.T. Redox-Active Metals, Oxidative Stress, and Alzheimer's Disease Pathology. Ann. N. Y. Acad. Sci. 2004, 1012, 153-163. [CrossRef] [PubMed]

95. Lin, H.J.; Wang, X.; Shaffer, K.M.; Sasaki, C.Y.; Ma, W. Characterization of H2O2-Induced Acute Apoptosis in Cultured Neural Stem/Progenitor Cells. FEBS Lett. 2004, 570, 102-106. [CrossRef]

96. Shin, S.Y.; Kim, C.G.; Jho, E.-H.; Rho, M.-S.; Kim, Y.S.; Kim, Y.-H.; Lee, Y.H. Hydrogen Peroxide Negatively Modulates Wnt Signaling through Downregulation of $\beta$-Catenin. Cancer Lett. 2004, 212, 225-231. [CrossRef]

97. Van Rossum, G.S.A.T.; Drummen, G.P.C.; Verkleij, A.J.; Post, J.A.; Boonstra, J. Activation of Cytosolic Phospholipase A2 in Her14 Fibroblasts by Hydrogen Peroxide: A P42/44MAPK-Dependent and Phosphorylation- Independent Mechanism. Biochim. Et Biophys. Acta-Mol. Cell Biol. Lipids 2004, 1636, 183-195. [CrossRef]

98. Zhu, D.; Tan, K.S.; Zhang, X.; Sun, A.Y.; Sun, G.Y.; Lee, J.C.M. Hydrogen Peroxide Alters Membrane and Cytoskeleton Properties and Increases Intercellular Connections in Astrocytes. J. Cell Sci. 2005, 118, 3695-3703. [CrossRef]

99. Abounit, S.; Zurzolo, C. Wiring through Tunneling Nanotubes-From Electrical Signals to Organelle Transfer. J. Cell Sci. 2012, 125, 1089-1098. [CrossRef]

100. Sun, X.; Wang, Y.; Zhang, J.; Tu, J.; Wang, X.J.; Su, X.D.; Wang, L.; Zhang, Y. Tunneling-Nanotube Direction Determination in Neurons and Astrocytes. Cell Death Dis. 2012, 3, e438. [CrossRef] [PubMed]

101. Rosich, L.; Montraveta, A.; Xargay-Torrent, S.; Lo'pez-Guerra, M.; Rolda 'n, J.; Aymerich, M.; Salaverria, I.; Bea', S.; Campo, E.; Pe'rez-Gala 'n, P.; et al. Dual PI3K/MTOR Inhibition Is Required to Effectively Impair Microenvironment Survival Signals in Mantle Cell Lymphoma. Oncotarget 2014, 5, 6788-6800. [CrossRef]

102. Wang, H.; Duan, L.; Zou, Z.; Li, H.; Yuan, S.; Chen, X.; Zhang, Y.; Li, X.; Sun, H.; Zha, H.; et al. Activation of the PI3K/Akt/MTOR/P70S6K Pathway Is Involved in S100A4-Induced Viability and Migration in Colorectal Cancer Cells. Int. J. Med Sci. 2014, 11, 841-849. [CrossRef] 
103. Xue, G.; Hemmings, B.A. PKB/Akt-Dependent Regulation of Cell Motility. J. Natl. Cancer Inst. 2013, 105, 393-404. [CrossRef] [PubMed]

104. Chauveau, A.; Aucher, A.; Eissmann, P.; Vivier, E.; Davis, D.M. Membrane Nanotubes Facilitate Long-Distance Interactions between Natural Killer Cells and Target Cells. Proc. Natl. Acad. Sci. USA 2010, 107, 5545-5550. [CrossRef] [PubMed]

105. Bellacosa, A.; Kumar, C.C.; Cristofano, A.D.; Testa, J.R. Activation of AKT Kinases in Cancer: Implications for Therapeutic Targeting. Adv. Cancer Res. 2005, 94, 29-86. [CrossRef] [PubMed]

106. Hao, Y.; Wong, R.; Feig, L.A. RalGDS Couples Growth Factor Signaling to Akt Activation. Mol. Cell. Biol. 2008, 28, $2851-2859$. [CrossRef]

107. Fruman, D.A.; Chiu, H.; Hopkins, B.D.; Bagrodia, S.; Cantley, L.C.; Abraham, R.T. The PI3K Pathway in Human Disease. Cell 2017, 170, 605-635. [CrossRef] [PubMed]

108. Pasquale, V.; Ducci, G.; Campioni, G.; Ventrici, A.; Assalini, C.; Busti, S.; Vanoni, M.; Vago, R.; Sacco, E. Profiling and Targeting of Energy and Redox Metabolism in Grade 2 Bladder Cancer Cells with Different Invasiveness Properties. Cells 2020, 9, 2669. [CrossRef] 